دور البيلنت والمعلوملت المحلسبية في الخاذ الفرارل بالشرككت الحكومية المصربة

درلسة حالة: الشركة العامة الصولمع والتخزين

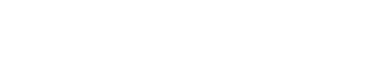

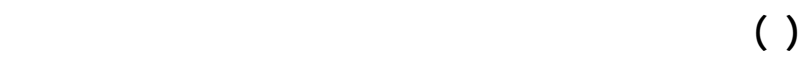

معدلات الأجور، وبرجع ذك نتيجة لهيمنة الأجور عل هيل المئل

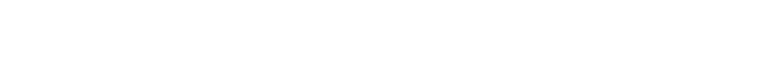
نحو الج,

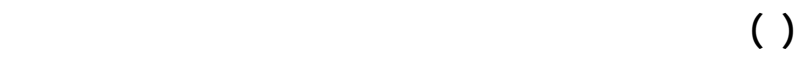

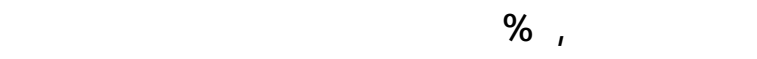

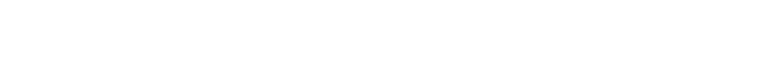

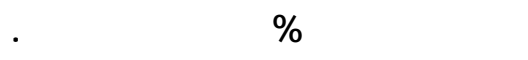

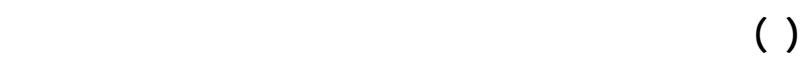

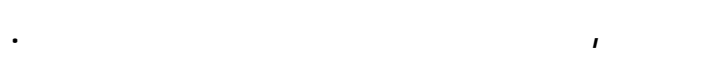

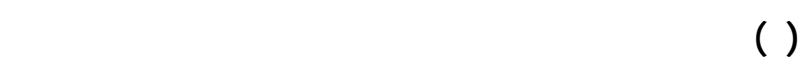

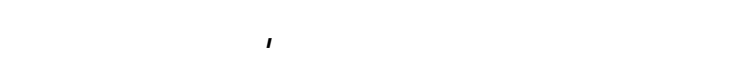

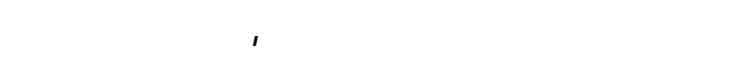
الفترة، مما يعفي عمم قدرة القية علمسداد الإلتزالمات.

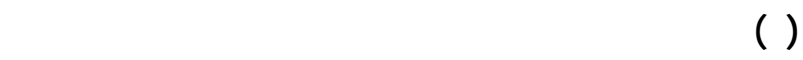

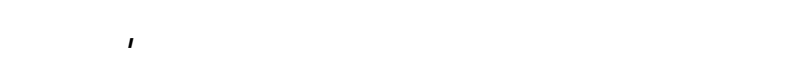
متوطط الفترة. مماعسق تبين لن الهيل التموبلية والمالية بالثركة تعلي العيدمن ظلاهر الظل والفصور، ومن ث م متزلي 2 الحتم اللات

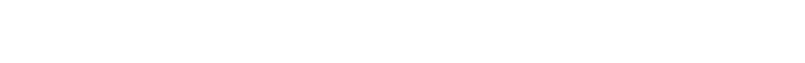

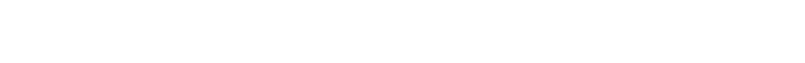

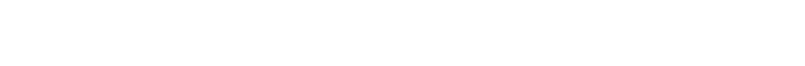

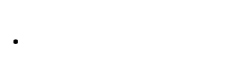

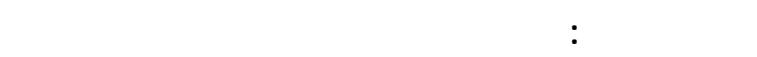
المعلوملت، المؤشرات المالية.
المالضص العرى

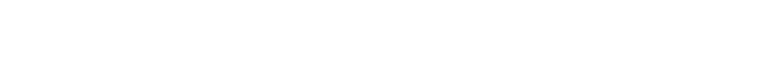

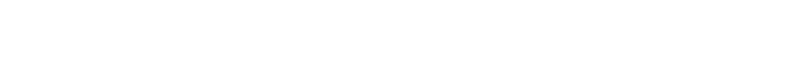

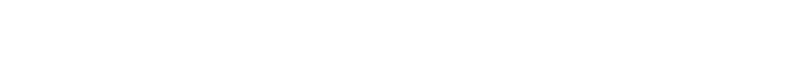

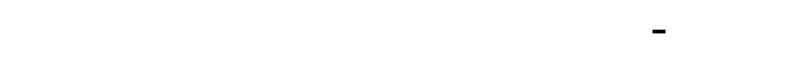

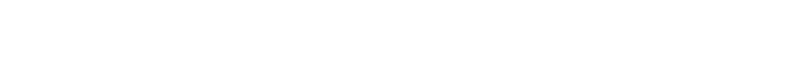

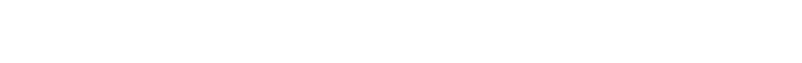

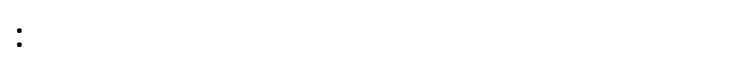

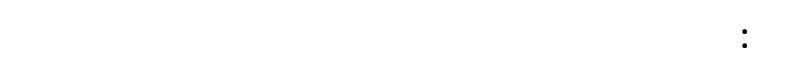

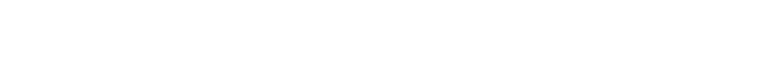

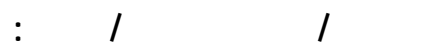

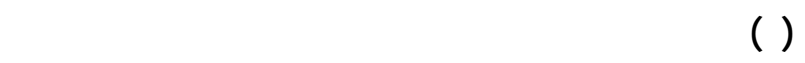

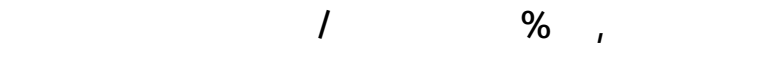

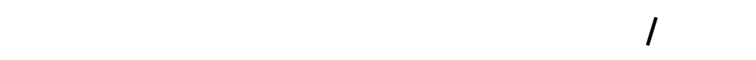

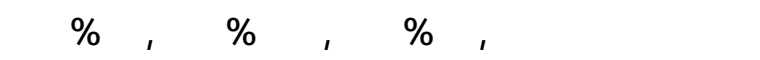

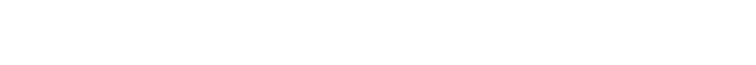

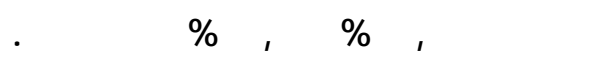

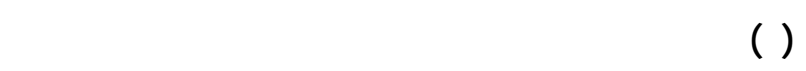

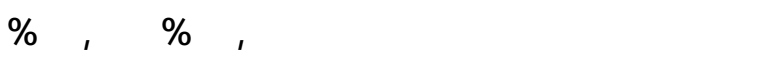

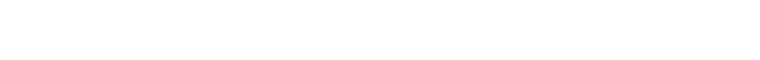

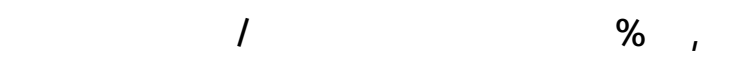

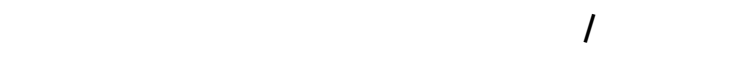

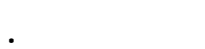

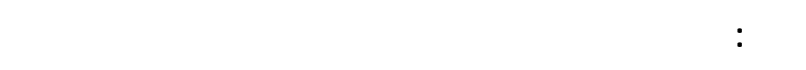

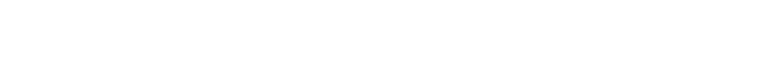

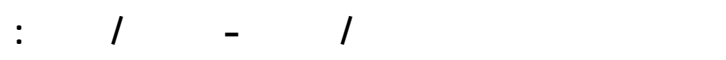

1مدرس قسم القتصاد وإدارة الأعمل الزراعية، كلية الزراعة، جلمعة الإسكندرية. Email: Sameh.shehab@alexu.edu.eg

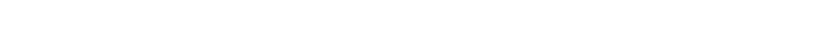




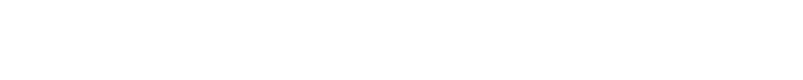

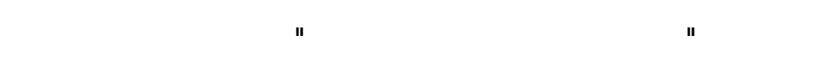

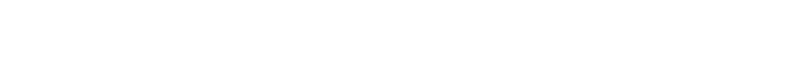

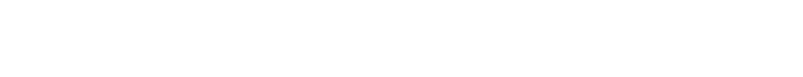

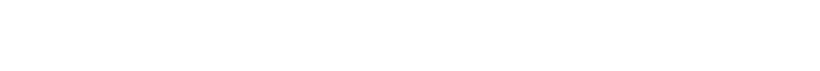

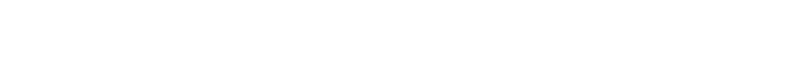
بعض المنازعلت القضائية المظورة أملم الجهات القضائية

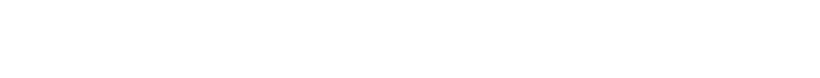

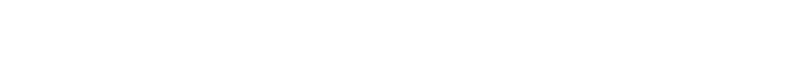

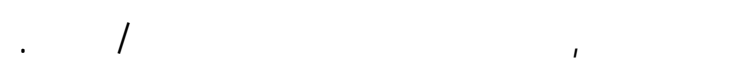

\section{أهيل البهث}

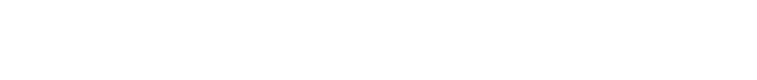
والمعلوملت المحلسبية فى التخاذ القرارات الإدارية والمالية،

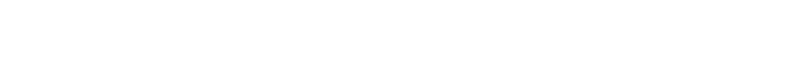

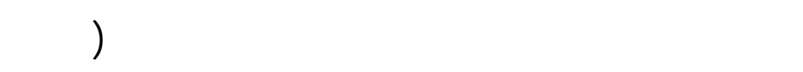

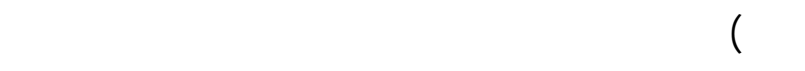

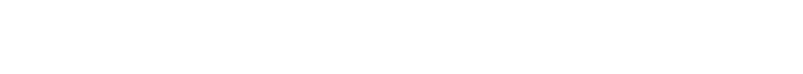

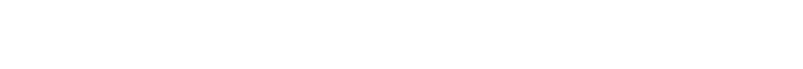

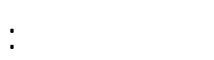

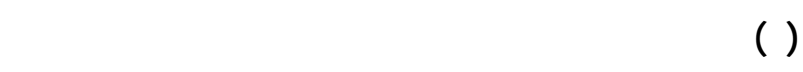

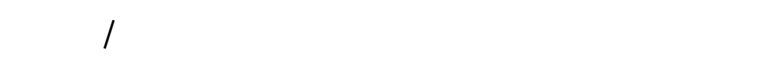

$$
\text { r. } .|\varepsilon / r \cdot| r
$$

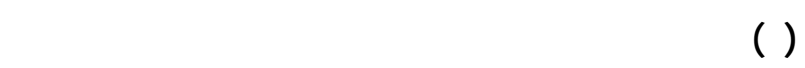

$$
\text { الفترة } 1 \text { · · }
$$

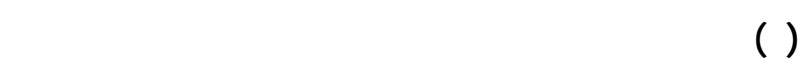

$$
\text { الفترة م. • }
$$

(ع) وصف وتحللي وقييم الخصائص المالية والإحصائية للهيللك

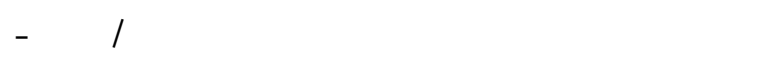

\section{المقمة}

تشهد المؤسست الاقتصادية قطورات عالمي ةس -ريعة

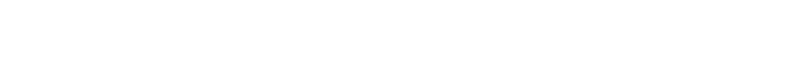

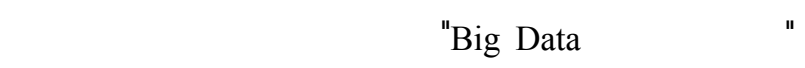

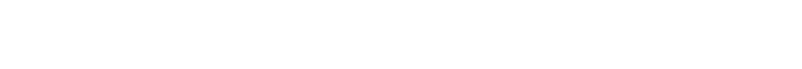
الاقتصاد العالمي خاصة مع القص الـ ششيد ف عي الم ـوارد الاقتصادية، حيث يتوقف نجاح الثرركات على كفاءة وفعالية

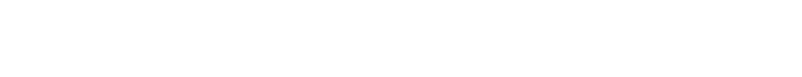

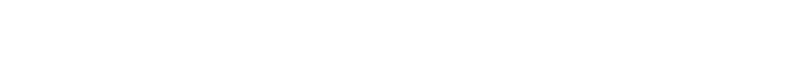

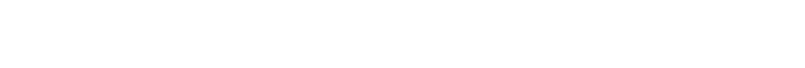

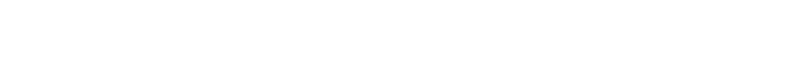

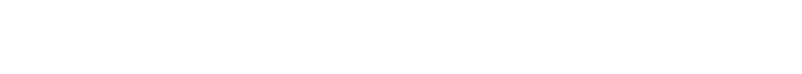

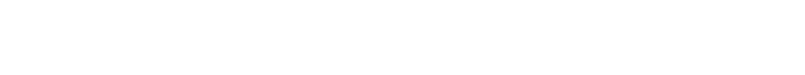
المزيج التمويلي.

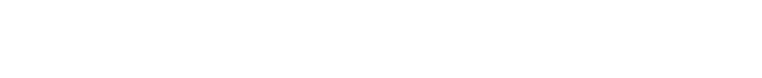

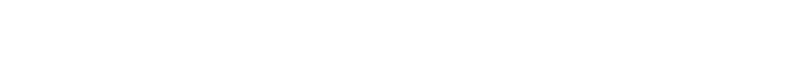

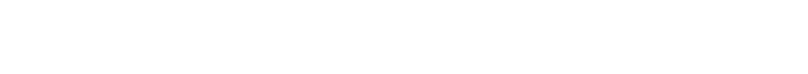

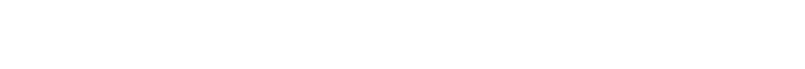

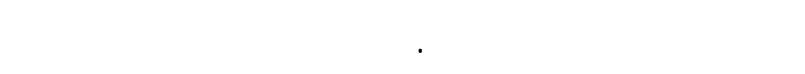

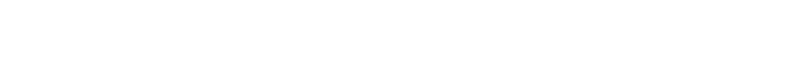

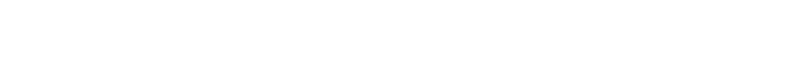

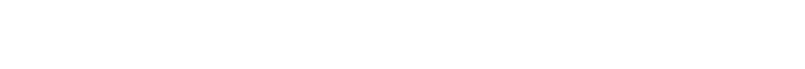

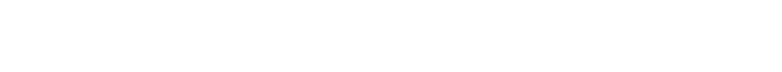

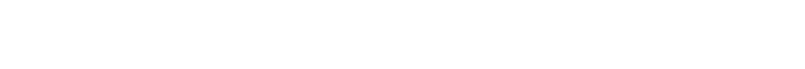
يعزز قدراتها التنلفية.

\section{مشكلة البهث}

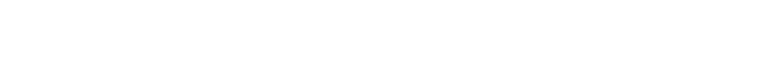

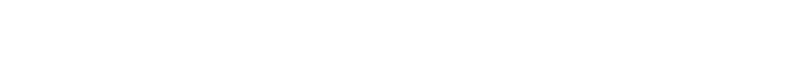
الظرر المعلوملت كعنصر حلكم ومحدد للقرارات، حيث أن الني

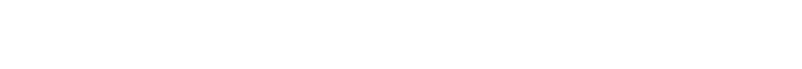

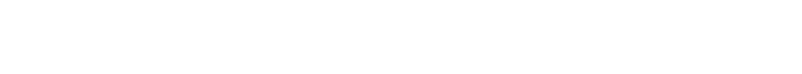




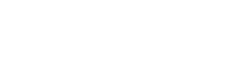

يستند البهث في تحقيق أهدله على الإبتعانة بألس اليب الئل

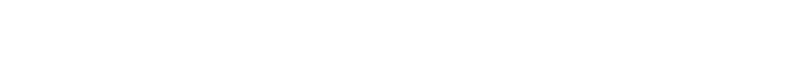

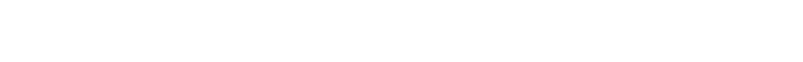

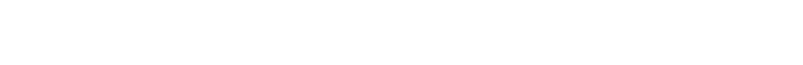

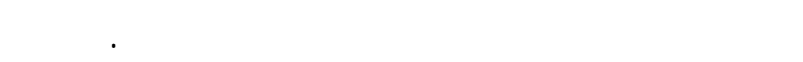

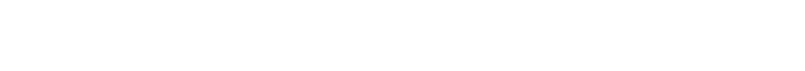
الشربكة.

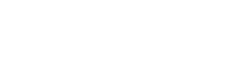

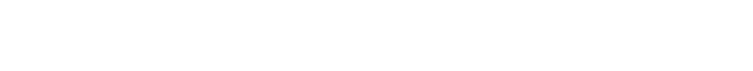
المالية والاقتصاية التي تمكن البلحث من الحصول عليها،

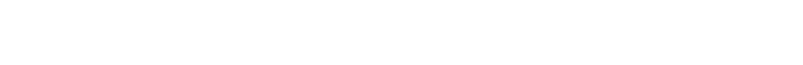

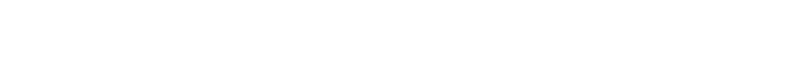

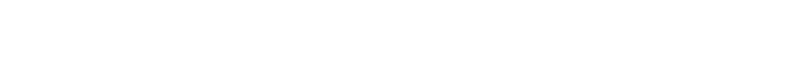

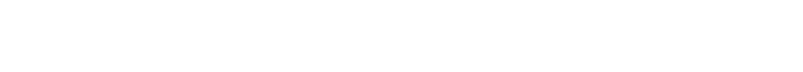
الدرلسلت والدوريات والمجلات العلمية والكت بب العربيية

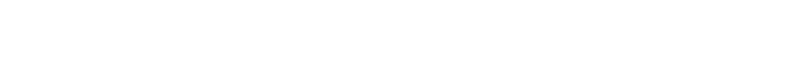

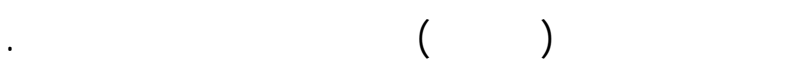

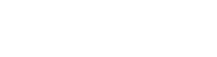

يتردد في مجل هـ ذا البح ثث العدي دمه ـن المف اهيم

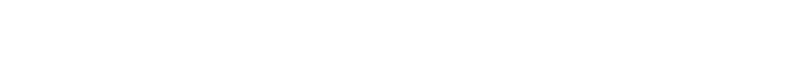

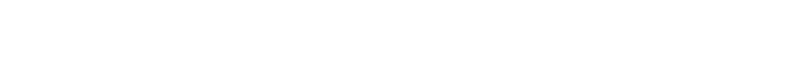
بين هذه المصطلحت والمفاهيم العلمية، وهي :

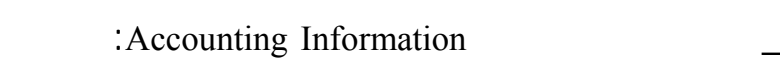
المخرجات الرئيسية لعملية المعالجة والنشغيل المظم المئة

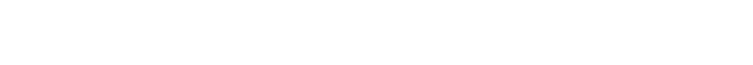

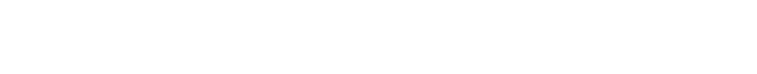

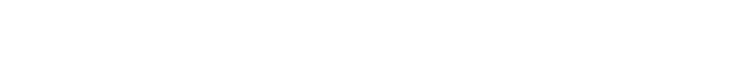

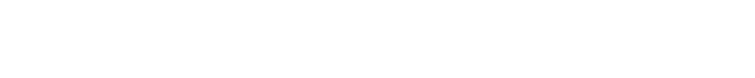

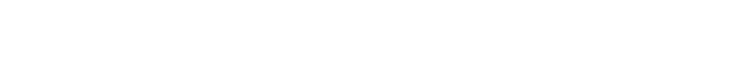
عدد من القارير المالية الأسلسية . علئ.

\section{أهمية ومبررك الجث}

Empirical يندرج هذا البحث فى فئة البحوث الطبيقية

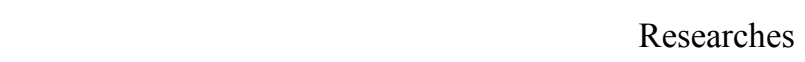
والمؤثرات المالية على اللثركة العلمة للصوامع والتخزين من خلال تحليل البيانت والمعلوملت المحلس ـبية الـ ـواردة بالقارير المالية بهوف الوقوف على قطل القوة والضف فى

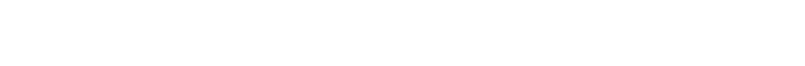
في تقيم أداء اللثركة والتخطيط للمسنقل وتحقيق أه دافها المالية (القاء، النمو، الإستمرار)، وصولاً لتحديد ما تظطلبه اللثركة من جهود للظوير. يُعد لختيار اللثركة العلمة للصوامع والتخزين - كدرلسة

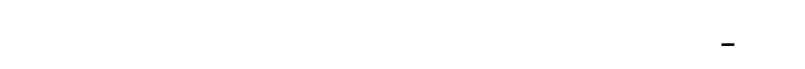
اللشركة المصرية القابضة للصوالمع والتخزين التابعة لوزارة

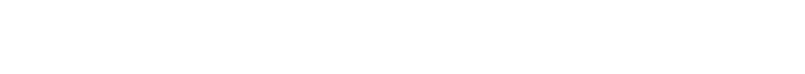
تعتبر لكبر اللثركك التي تمنك الأصول فى مصر، وتُع التُ 2

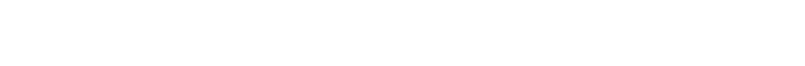

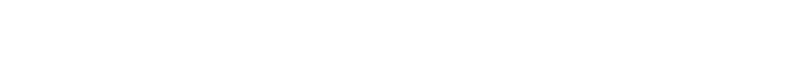

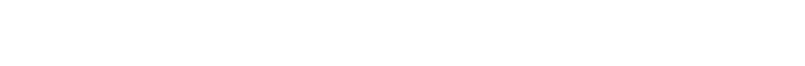

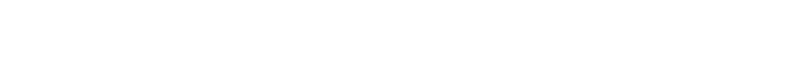
لإحتكارها مظطمشون وصولمع التخزين فى جميع المولنع

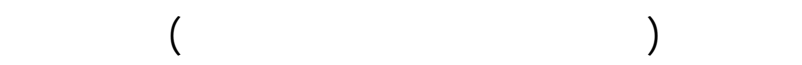

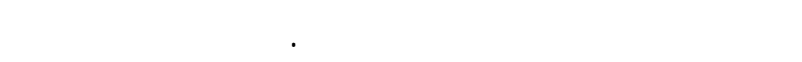

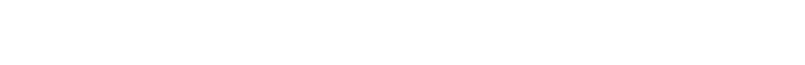

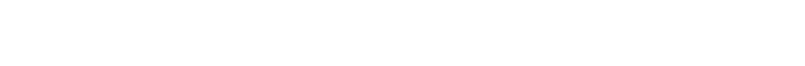

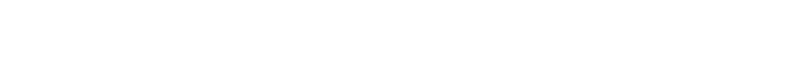

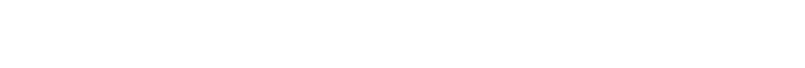
المشروع الإمارلتي لبناء ro صومعة كمنحة من الإمارات

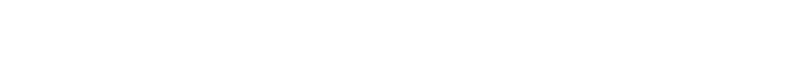

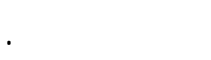




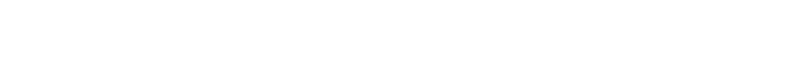

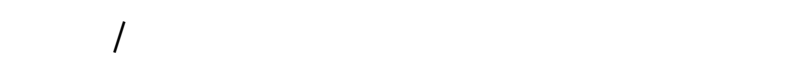

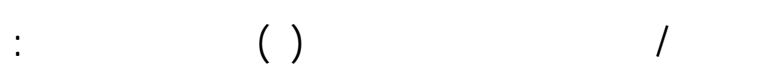

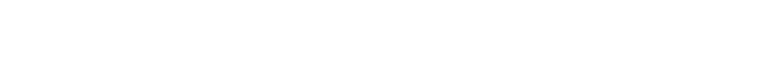

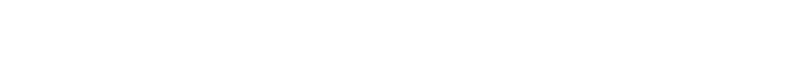

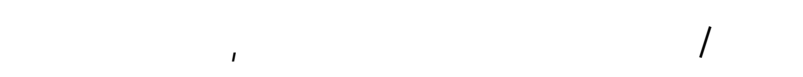

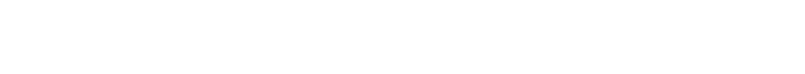

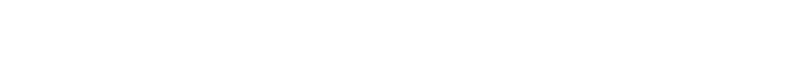

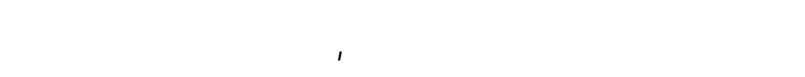

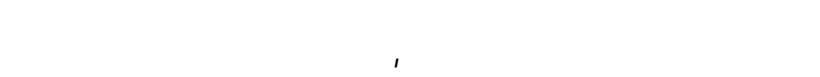

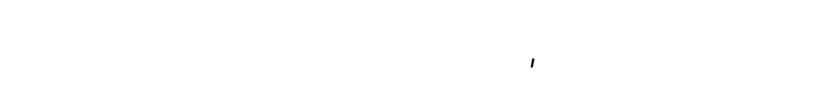

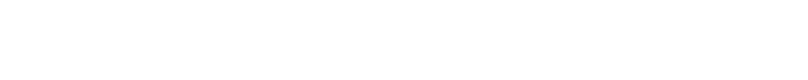

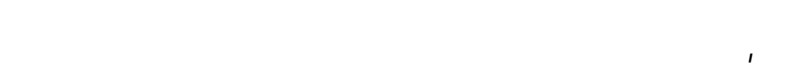

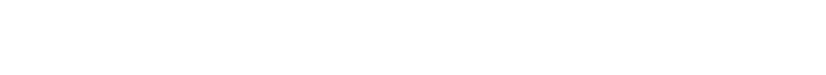

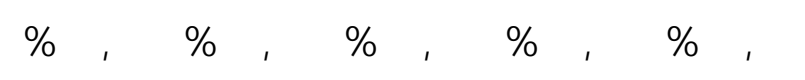

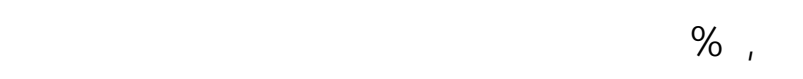
الأقماح اللشركة .

كما تبين بدرلسة الكميك الواردة من الأقماح التموينية

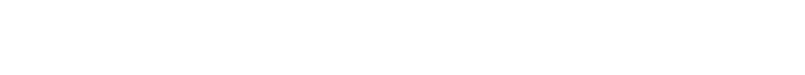

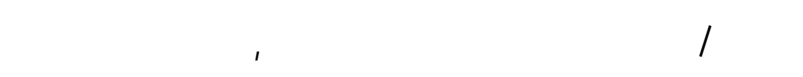

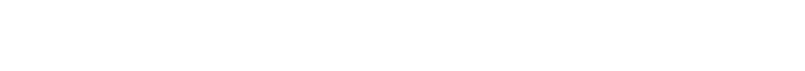
تنتمل في رومانيا، روسيا، أمريكا، فرنسا، أوكرانيا بكمية

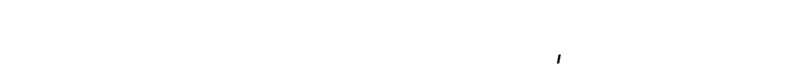

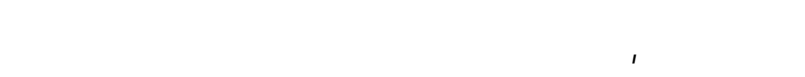

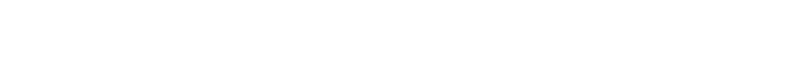

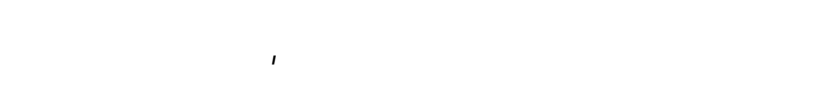

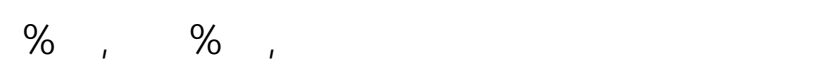

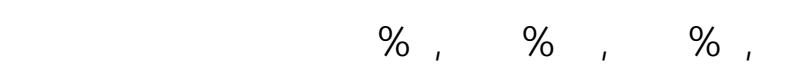

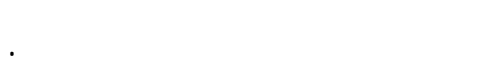

ـ الهيل التمويلي Finance Structure

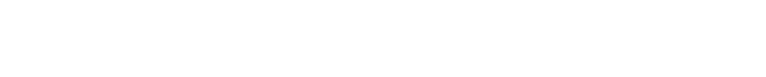

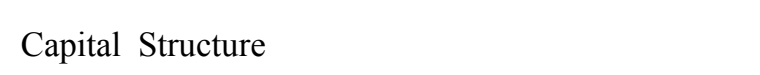

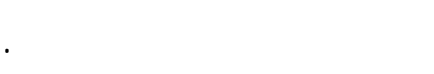

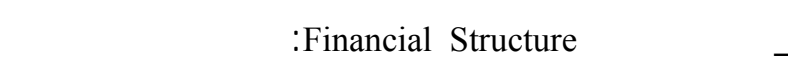

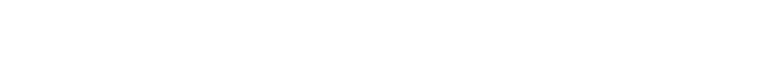

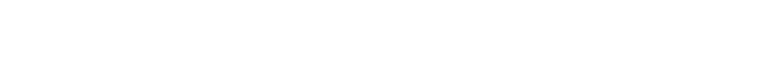

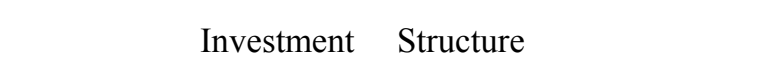

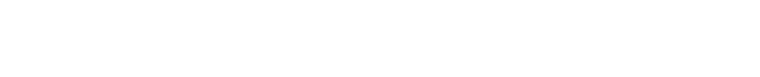

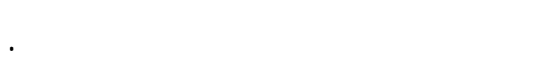
عنتخلص مماسبق أن العلاقة بين التمويل والإبد تثنمار

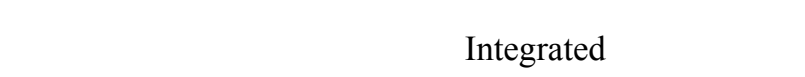

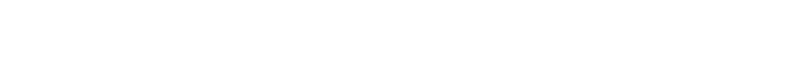

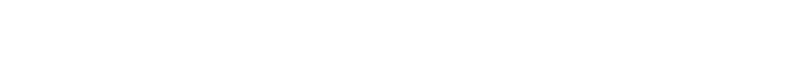

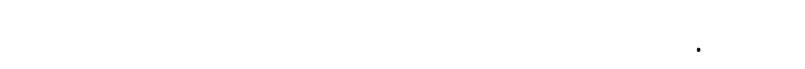

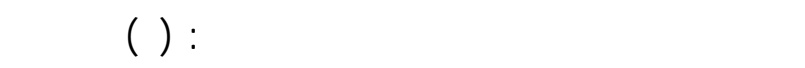

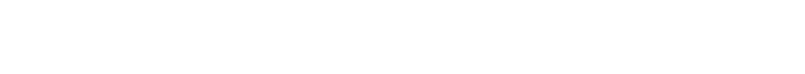

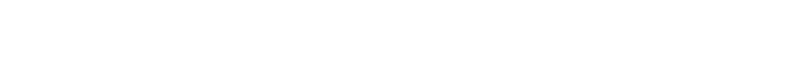

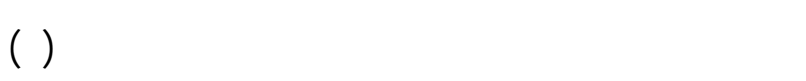

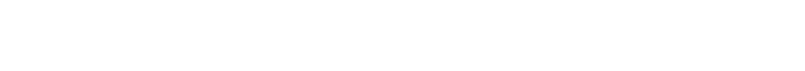

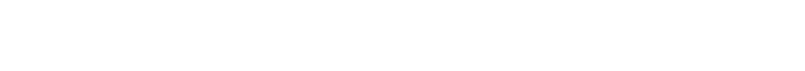

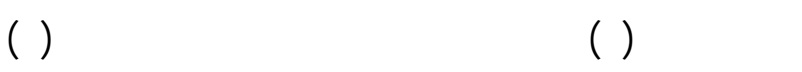

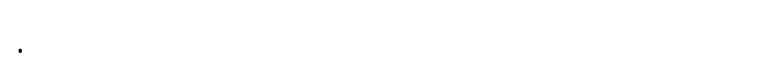

\section{النتائج البحثية ومنالشتها}

فيما يلي أهم نتائج أعمل ال ششركة العله ـة لل مصوالمع

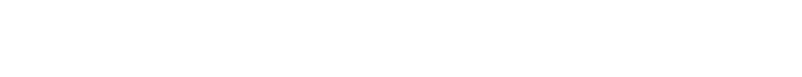
والقوائم المالية، وهى على النحو التالي:

\section{ألواً: الوضغع الراله للميلت الوارنة من الفماح الثموبنية الشركة العالمة للصولمع والنخزين:}

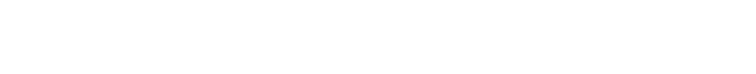

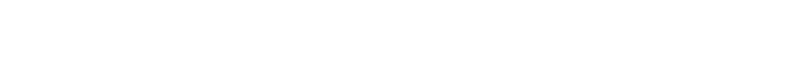




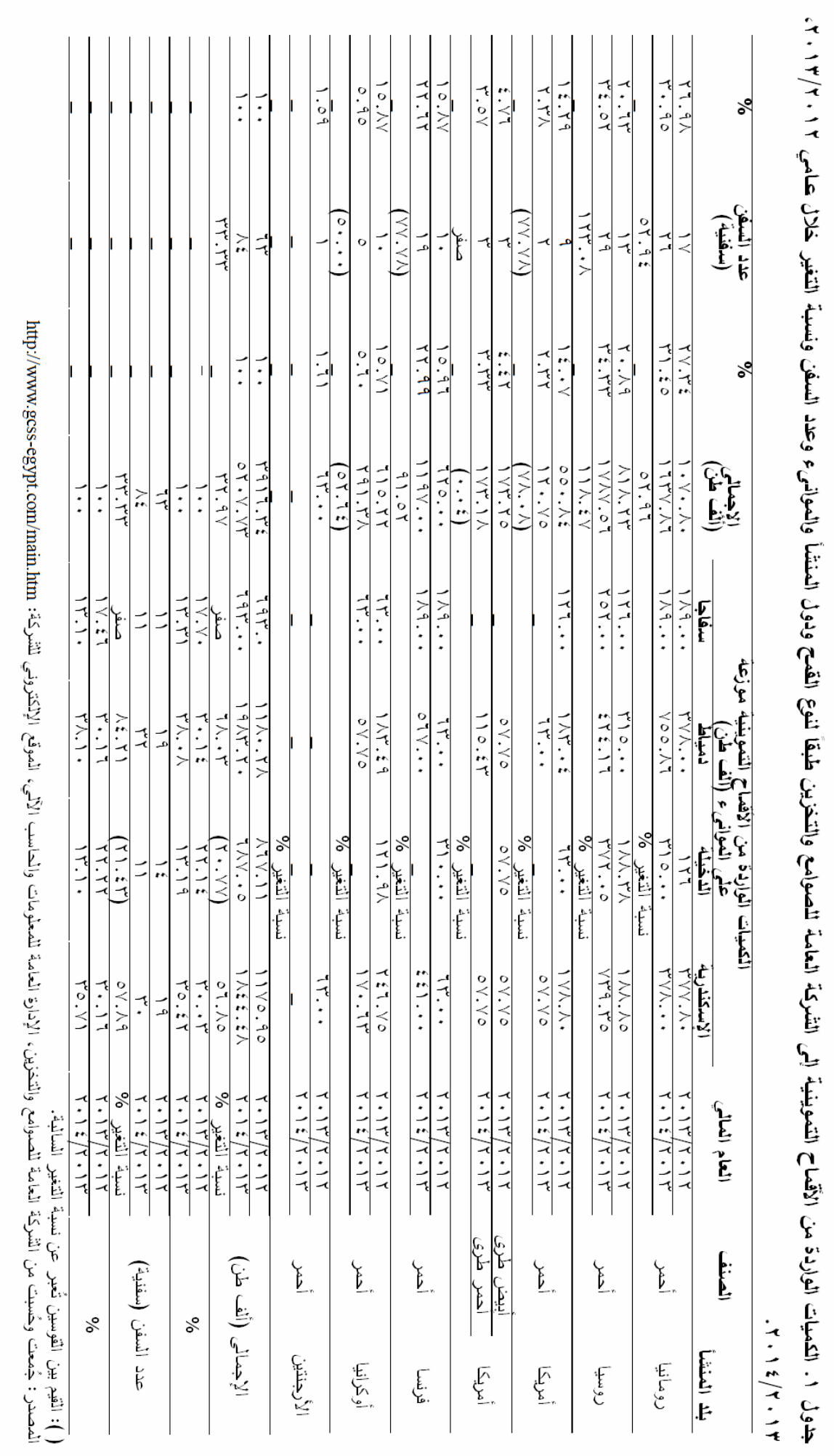




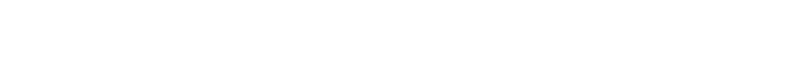

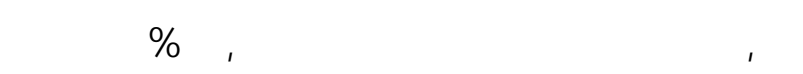
.

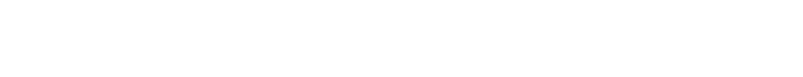

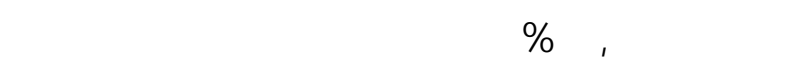

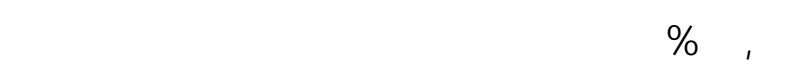

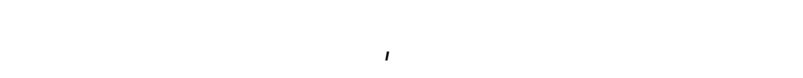

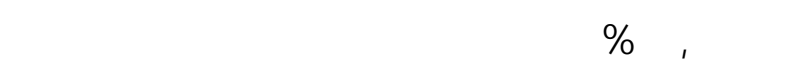
$\%|r$,$| .$

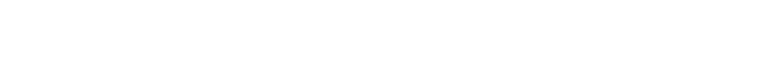

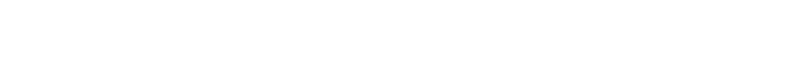

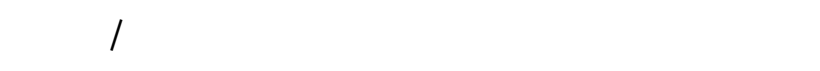

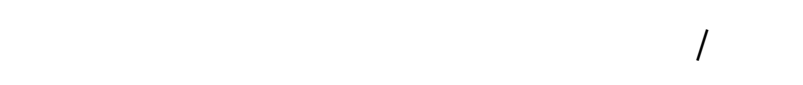

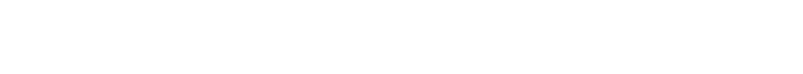

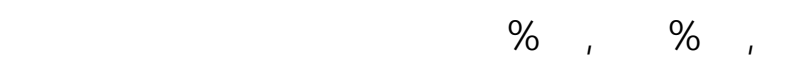

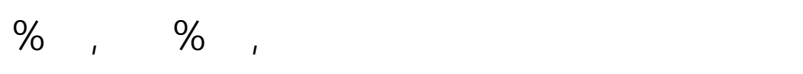

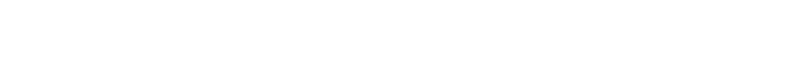

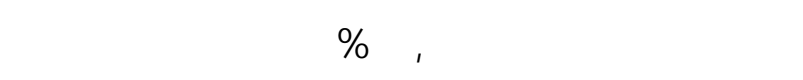

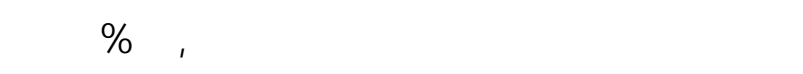

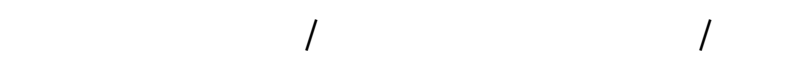

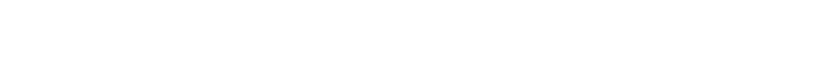
الأقماح إليه، وكذك عدد اللضن.

\section{ثلنياً: معالم ومؤشرات الوضع الرالهن اللهمالة بالشركة}

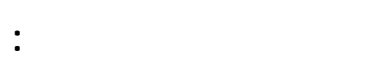

يُعد هذا المظور لحد التجاهلت بناء وقيلس وقفيم الأداء

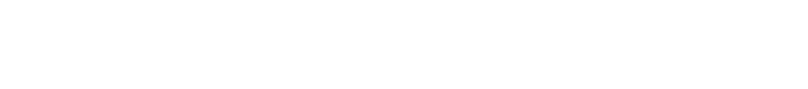

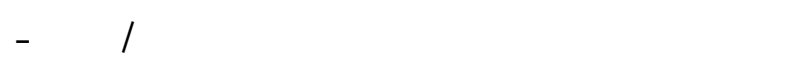

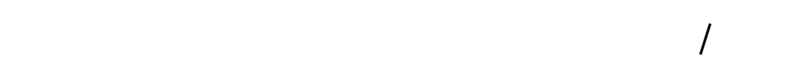

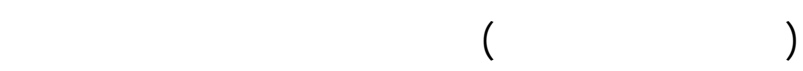

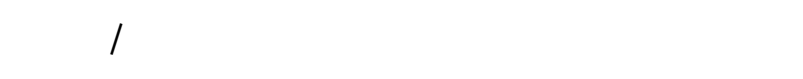

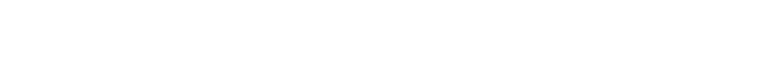
التمويني ـةطقة $]^{2}$

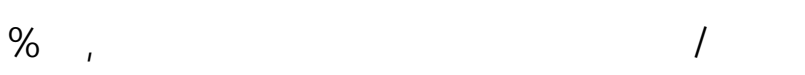

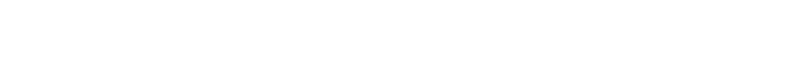

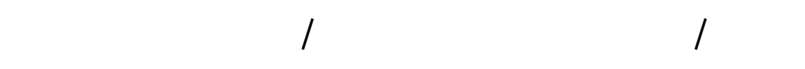

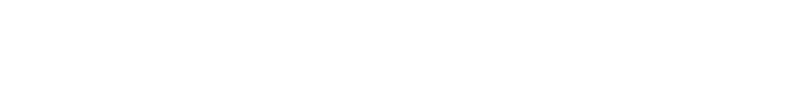

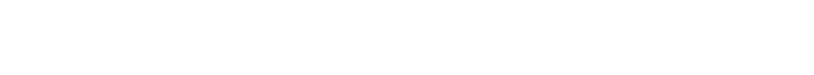

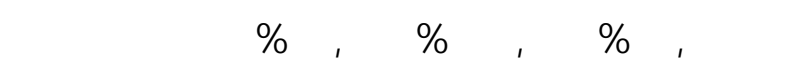

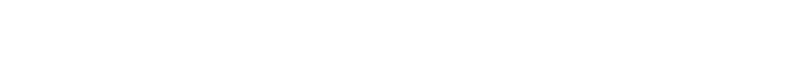

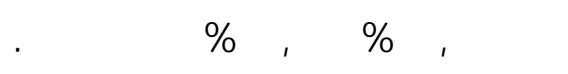

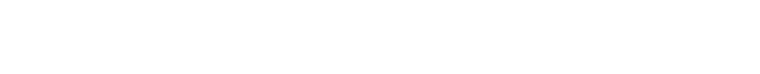

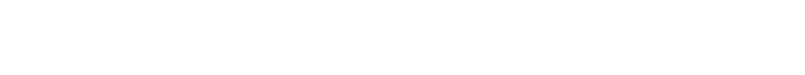

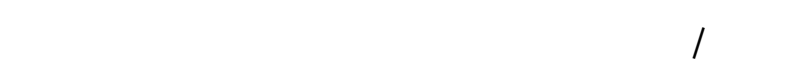

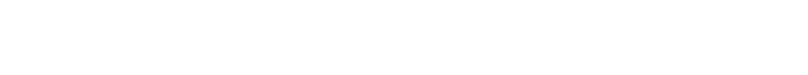

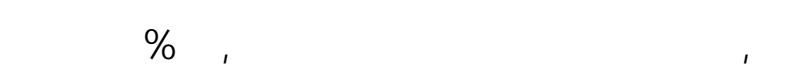

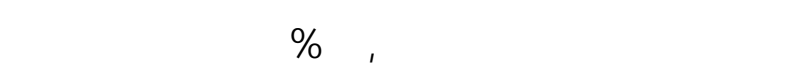

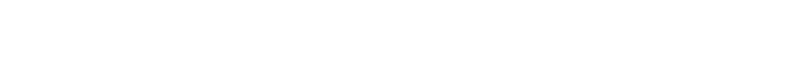

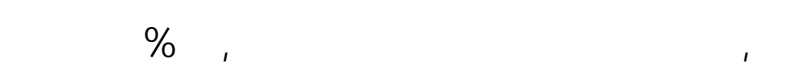

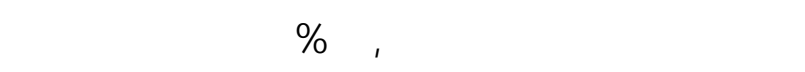
المرتبة الثالثة بكمية بلغت حوالي

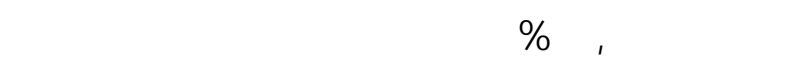

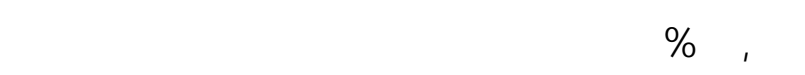

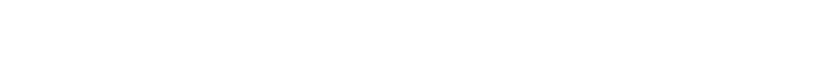

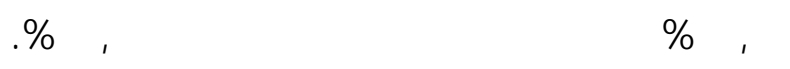

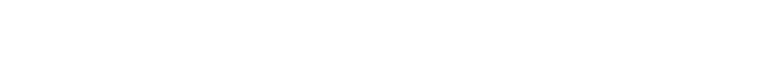

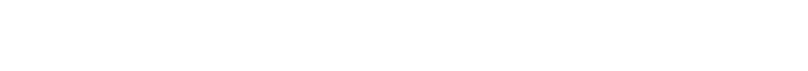

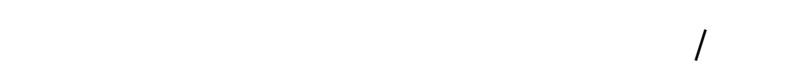

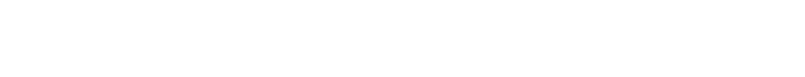

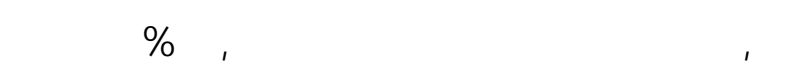

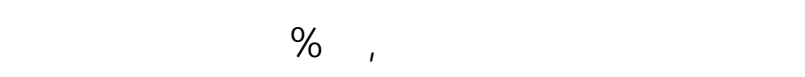




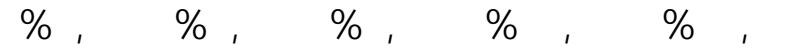

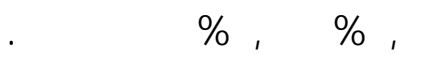

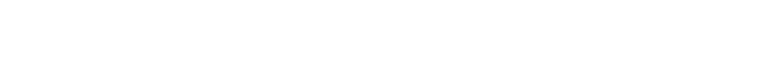

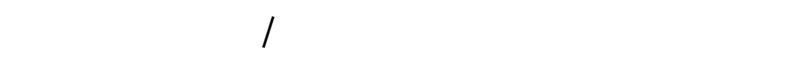

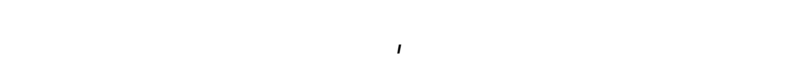

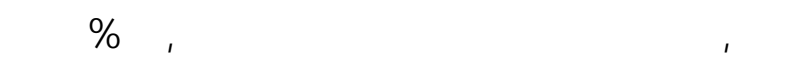

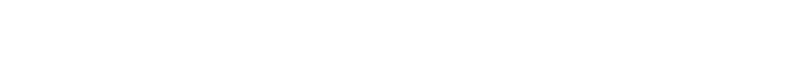

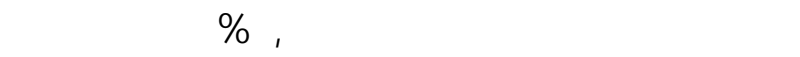

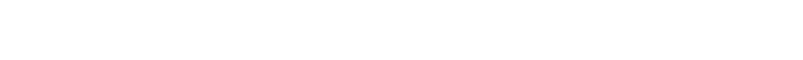
حوالي V عمل بنسبة بلغت نحو 7 ب, · \% موزعة عل م 1

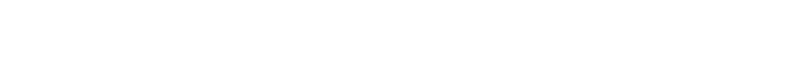

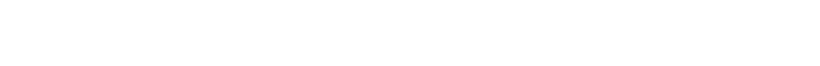

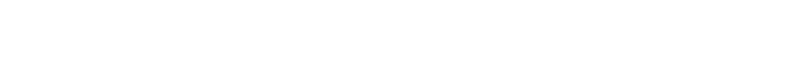
009 علمل، 009

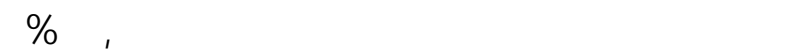

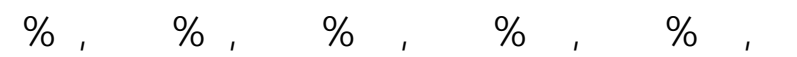
\% \%, IV بدرلسة نسبة التغير في العمالة بللثركة العلمة للصولمع

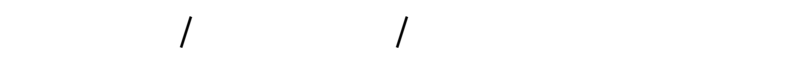
أن هنك إنخفاض في أعداد العلملين باللثركة بالعلم المالي

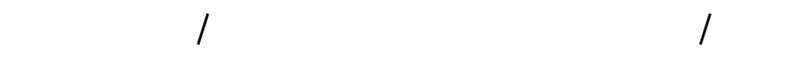
يمطي دلالة على إنخفاض معدل التوظيف كلحد المؤثرات

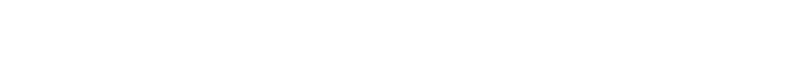
نحو ^ץ", ا \%، ولكن بصورة مفررةشهدت العمالة الدائم

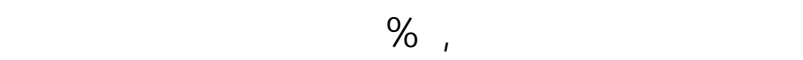

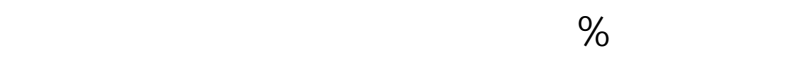

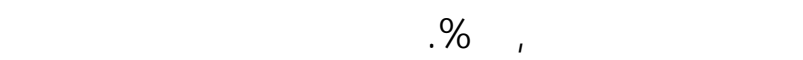
بين منطق الجمهورية تبين إتججه أعداد العلملين للإنخفاض

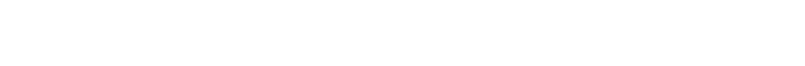

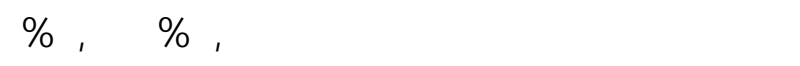

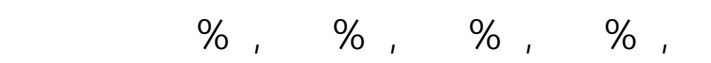

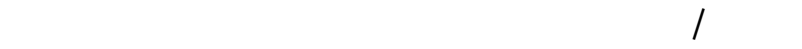
بجدولي (r)، (س) ما يلي: -عدد العاملين: بلغ متوسط عدد العلملين بللثركة العلم ـة

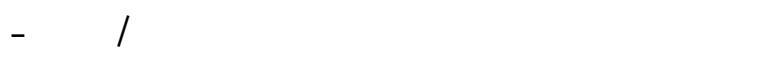

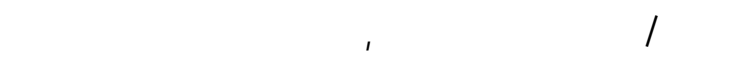
حوالي با

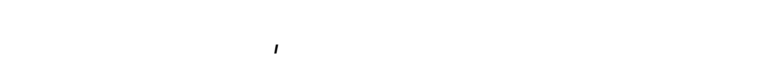

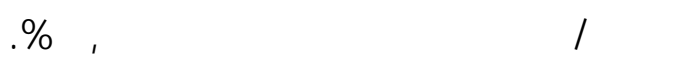
-معل التظليف: بدرلسة ظور معل التظفي بال شركة

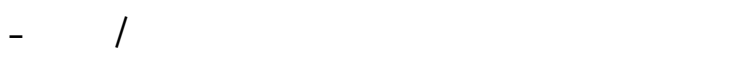

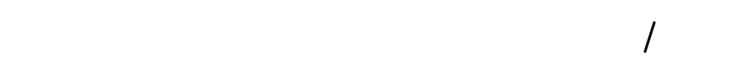

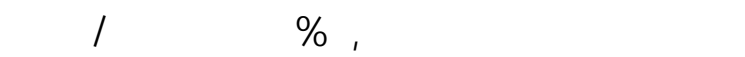

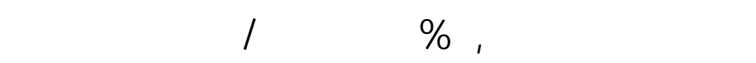

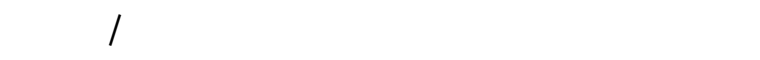

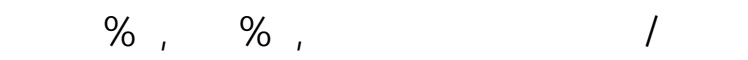
الترتيب.

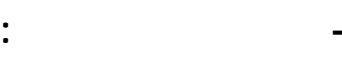

تبين بدرلسة الوضع الراهن للعمالة بال شرركة العلم ـة

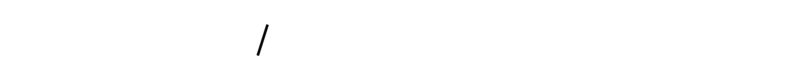

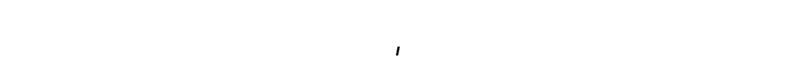

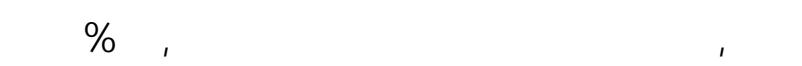
إجمالي العلملين بللثركة، بينما بلغ ع ـدد الع الملين بعق ـد

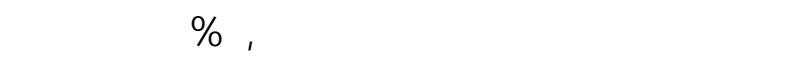

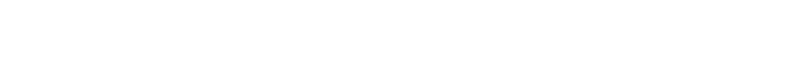

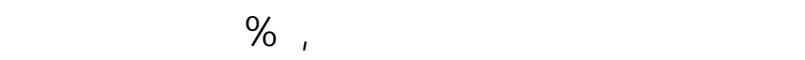
منطقق هـ الإسكندرية، الإدارة العلمة، الق اهرة، مي لطا،

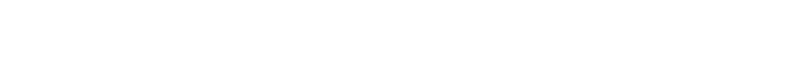

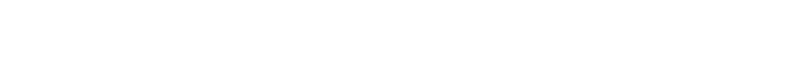

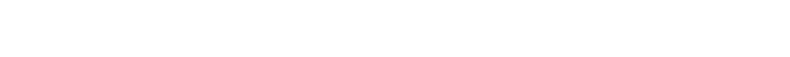

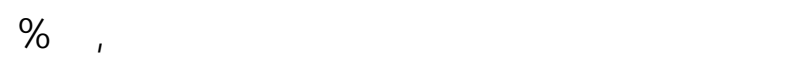




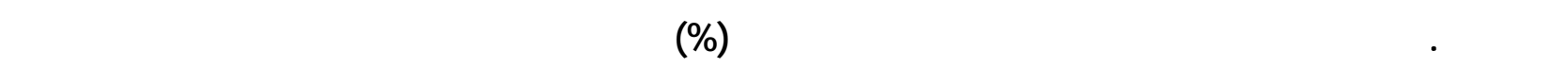

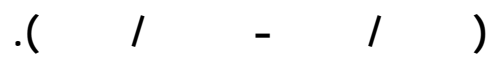

\begin{tabular}{|c|c|c|c|c|c|c|c|}
\hline l المتوطb & r.10/Iع & r.IE/Ir & r/ואון & r. & r.1//1. & r.1./.9 r..9/./ & العل الملال \\
\hline r,v99 & $r, 70 r$ & $r, 7 \wedge 9$ & $r, 7 \vee 7$ & $r, \wedge \mu q$ & $r, 91 r$ & $r, q 1 \mu$ & عدد العلملين \\
\hline & $(1, \mu \Lambda)$ & $\cdot \varepsilon q$ & $(0, V \varepsilon)$ & $(1,01)$ & $\cdot, \cdot \mu$ & $(\cdot, Y V)$ & معدل التوظف \\
\hline
\end{tabular}

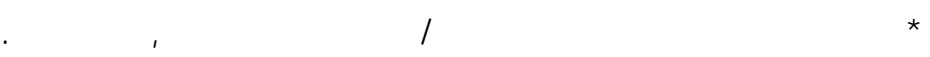

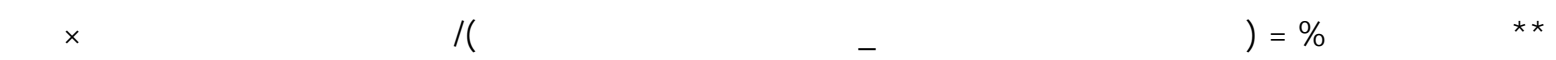

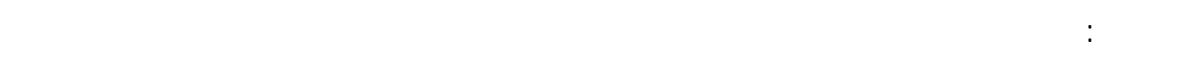

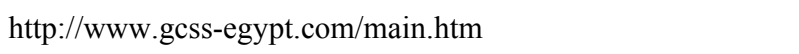

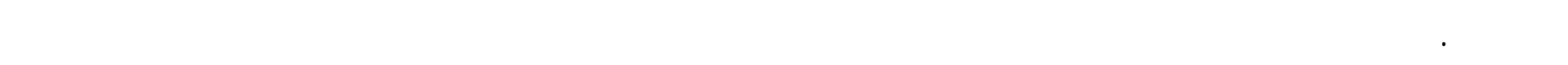

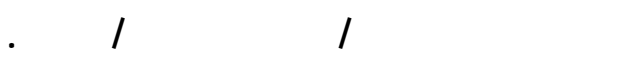

\begin{tabular}{|c|c|c|c|c|c|c|c|c|c|c|c|}
\hline \multirow{2}{*}{ النغبر } & \multicolumn{2}{|c|}{ الأهمية النسبية \% } & \multicolumn{2}{|c|}{ (بالزجمالل) } & \multicolumn{2}{|c|}{ ظهورت (بالعالل) } & \multicolumn{2}{|c|}{ عقد (بالعلل) } & \multicolumn{2}{|c|}{ دأم (بالعالل) } & \multirow{2}{*}{ المظاقة } \\
\hline & $\begin{array}{c}\text { / } 1 \varepsilon \\
\text { r. } 10\end{array}$ & $\begin{array}{l}\text { /Ir } \\
\text { r.|ع }\end{array}$ & $\begin{array}{c}/ 1 \varepsilon \\
r \cdot 10\end{array}$ & $\begin{array}{l}\text { /I } \\
\text { r. }\end{array}$ & $\begin{array}{l}\text { /1ع } \\
r \cdot 10\end{array}$ & $\begin{array}{l}\text { /Ir } \\
\text { r. }\end{array}$ & $\begin{array}{c}/ 1 \varepsilon \\
r \cdot 10\end{array}$ & $\begin{array}{c}/ \boldsymbol{I} \\
\boldsymbol{r} \cdot \boldsymbol{L}\end{array}$ & $\begin{array}{c}/ 1 \varepsilon \\
r \cdot 10\end{array}$ & $\begin{array}{c}/ \boldsymbol{I} \\
r \cdot \mid \varepsilon\end{array}$ & \\
\hline$\left(1, १^{\mu}\right)$ & $r I, \cdot \Lambda$ & $r ו, r$. & 009 & ov. & - & _ & IV & $\varepsilon$. & OER & $\mathrm{Or}^{\mathrm{r}}$. & الإدارة العلمة \\
\hline$(0,91)$ & IV,Er & $11, r 7$ & $\varepsilon 7 r$ & દ१। & 1 & $\mu$ & 11 & r & عo. & $\varepsilon 07$ & القاهرة \\
\hline$(7,7 \Lambda)$ & $r \varepsilon, r \varepsilon$ & $r 0,7 r$ & $7 \varepsilon \mu$ & 719 & 0 & 1 & $r$ & rq & $7 \mu$ & ๆદ૧ & الإسكندرية \\
\hline$(q, \varepsilon))$ & $7,9$. & $\mathrm{V}, 01$ & $1 \Lambda \mu$ & $r \cdot r$ & - & - & $\mu$ & $r \varepsilon$ & 11. & IVA & بوبسعيد \\
\hline$\mu \mathrm{V}, \varepsilon$. & 14,17 & $૧, \varepsilon 0$ & ץદ૧ & roE & 1 & 1 & 1 & ir & reV & rEl & ميطا \\
\hline$\varepsilon, \wedge \Lambda$ & $\mu, r \varepsilon$ & $\mu, 0$ & 17 & $\Lambda r$ & _ & - & 11 & $\Lambda$ & $7 \Lambda$ & 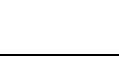 & للسويب \\
\hline$(7, \Lambda \cdot)$ & $\Lambda, \mathrm{V} 9$ & $9, \stackrel{\mu}{ }$. & س & ro. & _ & _ & $r$ & $\mu$ & ו ו & riq & سفلجا \\
\hline$(q, Y V)$ & $0,1 V$ & $0,7 r$ & IrV & 101 & - & - & $r$ & $r$. & Iro & $|\mu|$ & قل الإسكندرية \\
\hline$(1, \Psi \wedge)$ & $1 \ldots$ & $1 \cdots$ & ror & rา१९ & $\mathrm{V}$ & 0 & 07 & $r \cdot 7$ & ro^9 & rદV^ & الإجماله \\
\hline
\end{tabular}

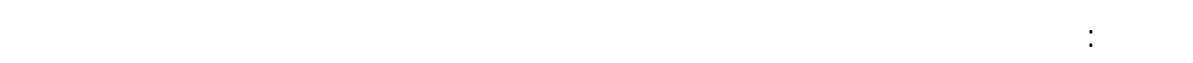

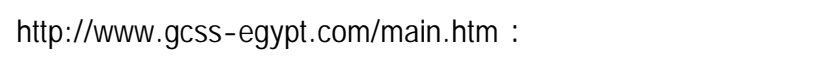

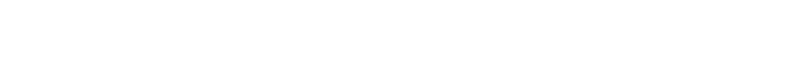
في حن إتجهت أعداد العلملين للزيادة في كل من لمي لطا،

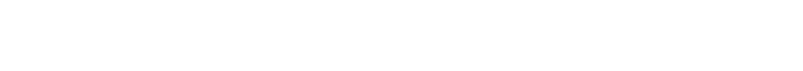
التكالف من خلل إمكانية تتغيضها والتحكم فيها، وقد تلجأ

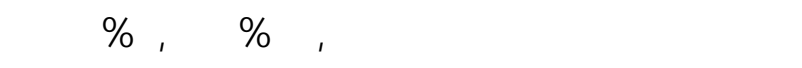
بعض اللثرككت إلى ظلم المعلث المبك ـر لتخف يض بض بذ ــ

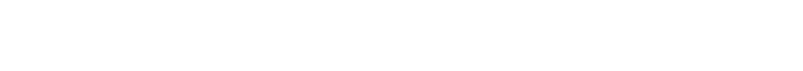

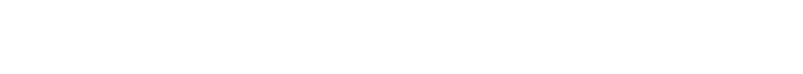

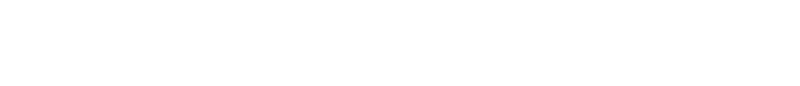

ثالثأة:معالم ومؤشرات الوضع الـ ـرلهن لهيك لل التك اليف بالشركة العامة الصوالمع والتخزني:

يعكس هيكل التكالف Cost Structure نسبة كل عن صر من عناصر التكالف، والتي تتمل ف مي تك اليف الإنت اجاج 


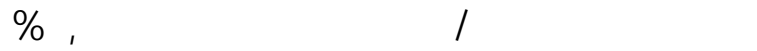

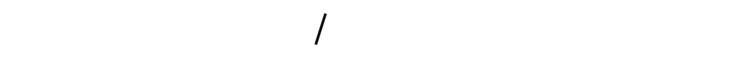

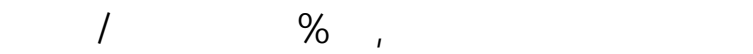

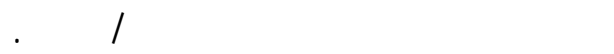

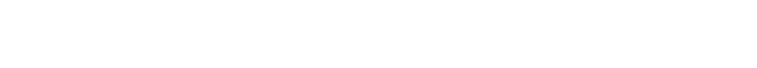

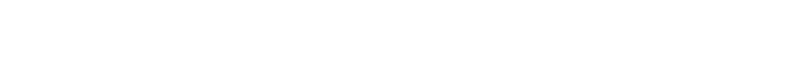
إلى خل في هيكل تكالف اللثركة، نتيجة هيمن ـة الأج -ور على هيكل التكالف، حيث وص لـ ن سسبة الأج -ور إل م

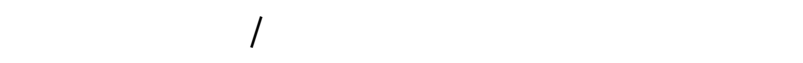
أ

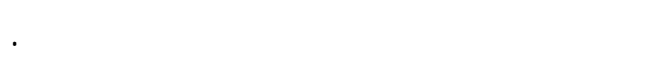

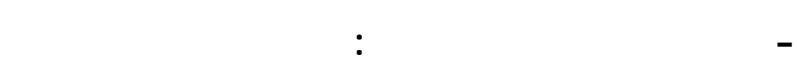

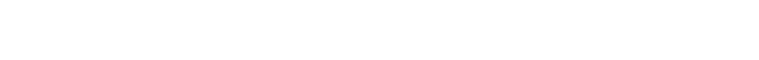

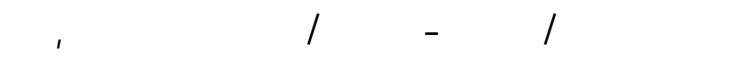

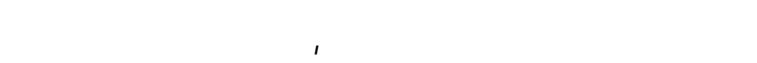

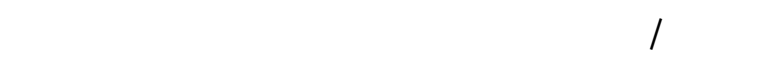

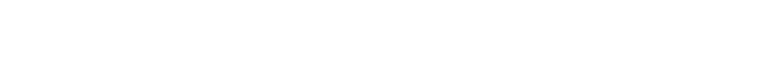

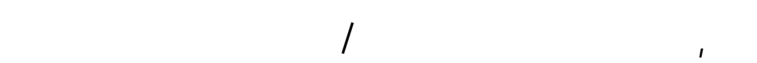
نحو $\%$ i

- رلس المل المففوع: بلغ متوس ط قيم ـة رلس الم لـ لـ

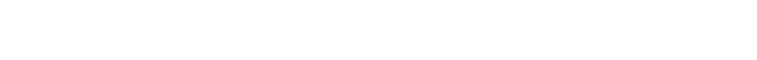

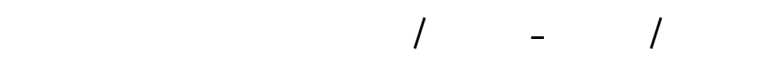
جنيه وقد إتنم بالثبات خلل فترة الدرلسة.

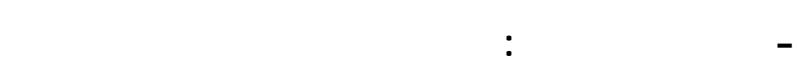

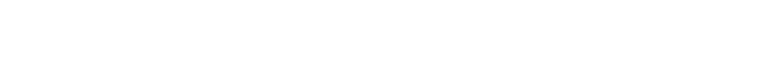

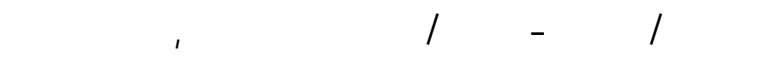

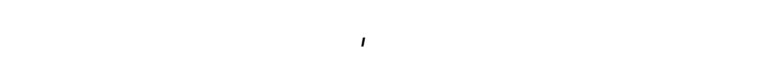

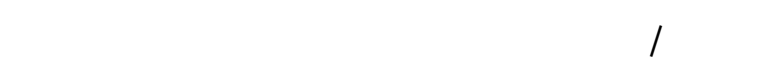

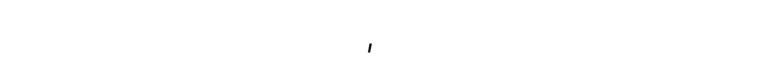

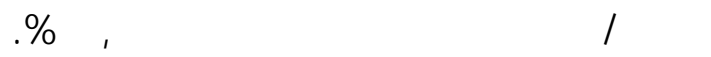

هذه الحالة فلِن للثركة تخفض من القروض ف مي هيكله L

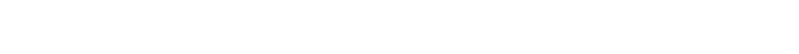
والمؤشررات الوارة بالجدول (ع) على النحو التالي : - الأجور: بلغ متوسط قيمة الأج -ور ال سسنوية للع الملن

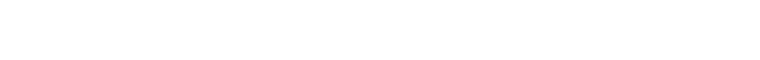

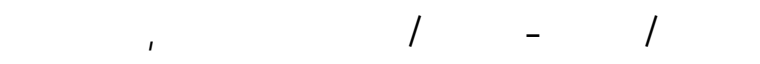

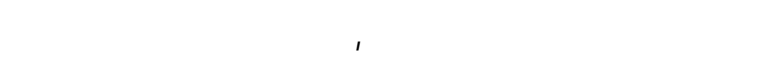

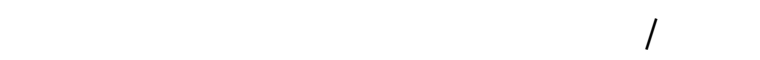

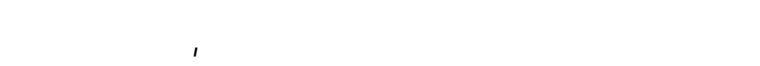

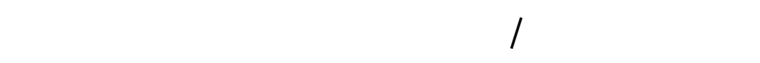
.\% $\urcorner \Lambda, \vee 0$

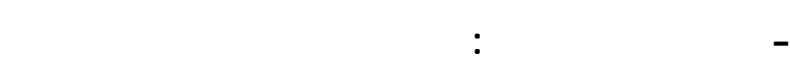
رضا العلملن بأنه مجموعة المشاءر - إيجابية وسلبية -

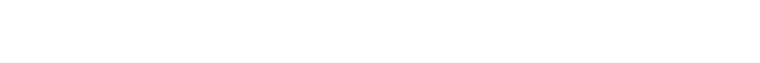

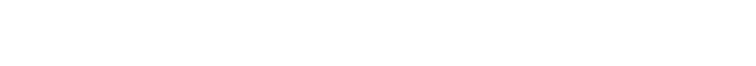
الأداء. حيث أن هنك علاقةطردية بين الرضا الوظيفي والأداء الوظيفي أي كلما إرقفع مستوى الرضاء الوظيفي

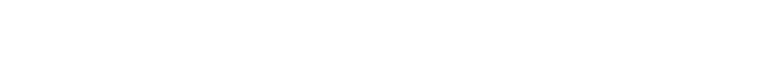

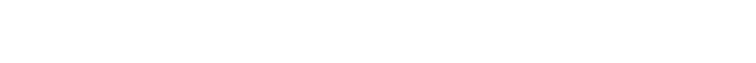

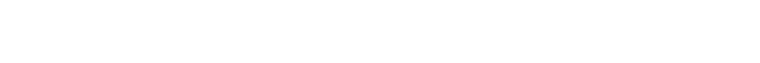

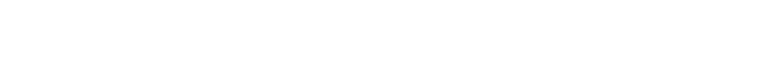

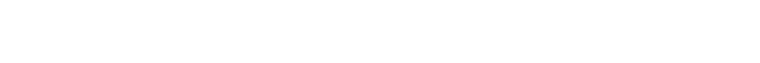

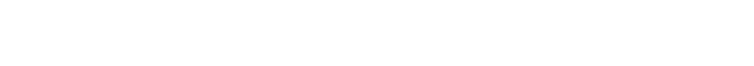

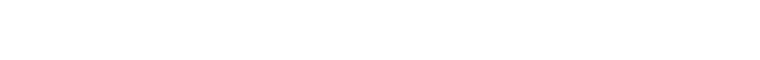

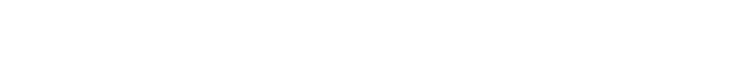

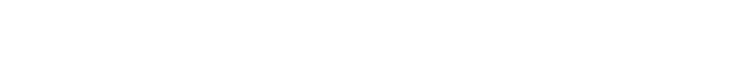

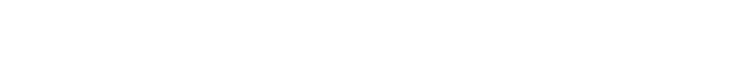
معل الأجر بملثرركة العلمة للصوامع والتخزين خ ـاله

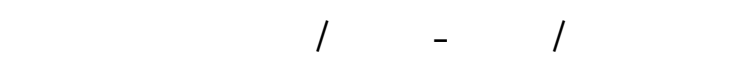

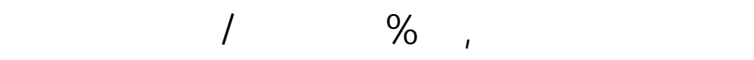

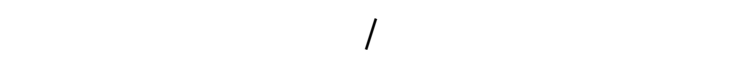




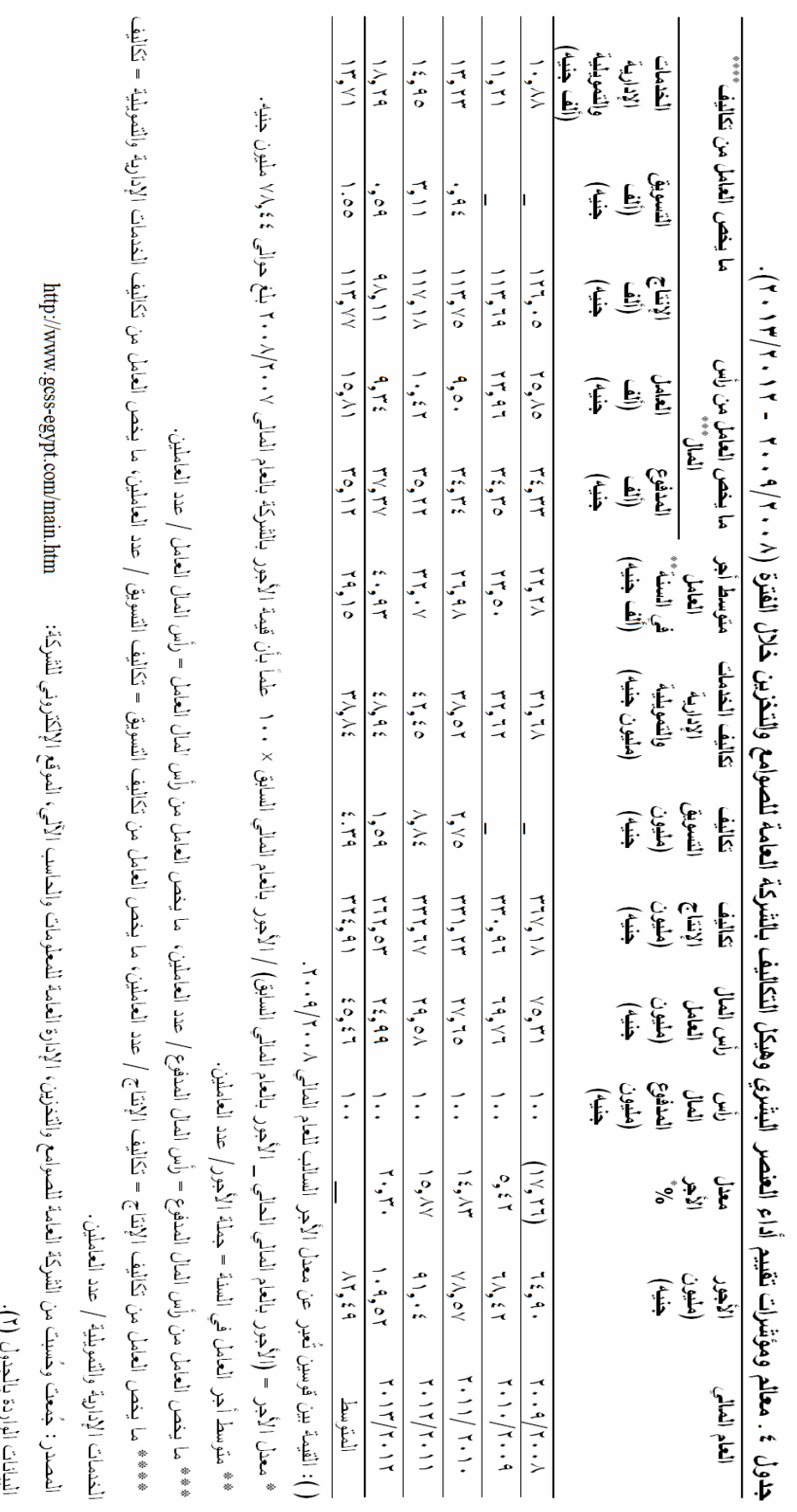


- تكالف الخملت الإداربة والتمويلية: بلغ متوبط تكالف الخملت الإدارية والتمويلية بللثركة العلمة للا صصولمع

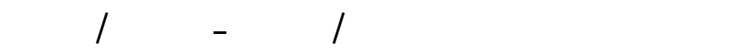

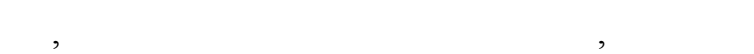

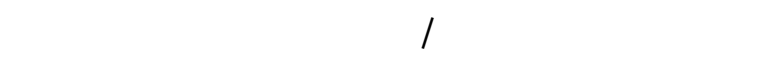

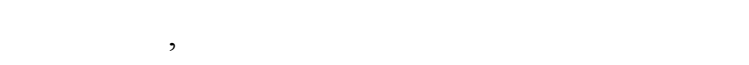

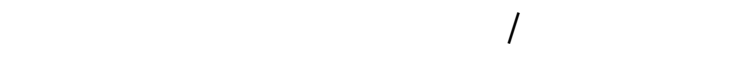

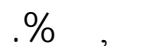

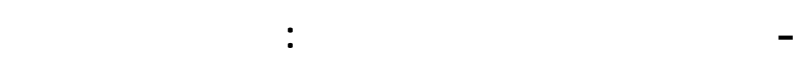

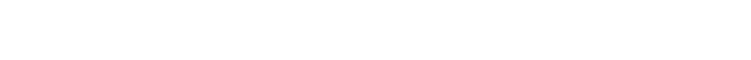

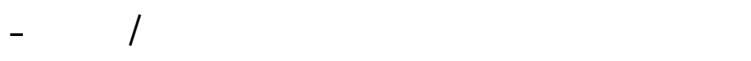

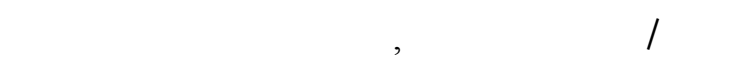

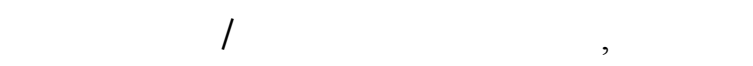
للإنخفاض ليطل إلى حوالي

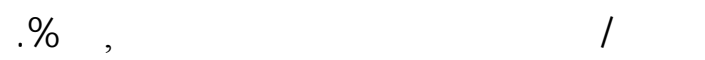

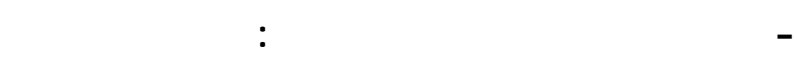
يخص العلمل من تكالف الت سويق بال ششركة العلم ـة

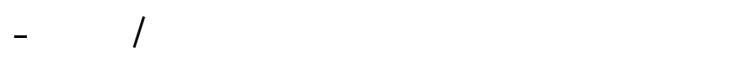

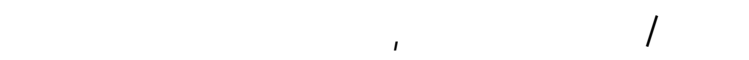

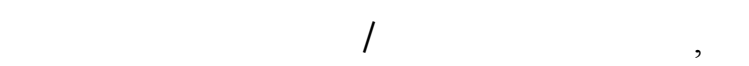

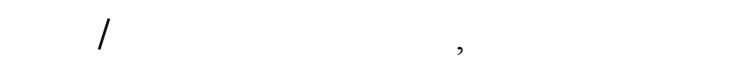

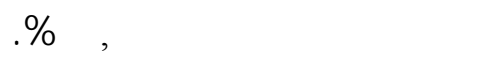

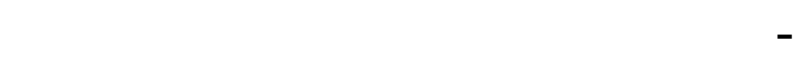

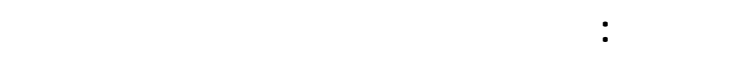
الخملت الإدارية والتمويلية بللشركة العلمة للا صصولمع

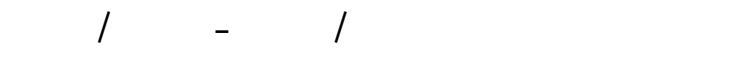

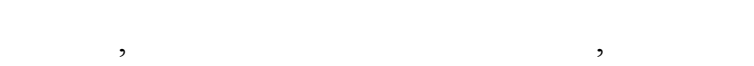

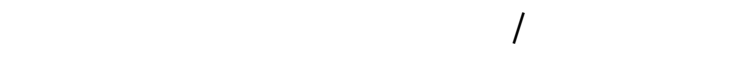

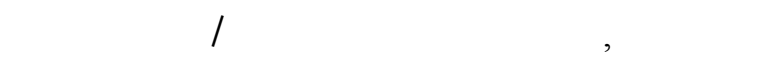

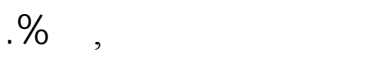

-ما يضص العللم رن رلس المل المفوع: بلغ متوبط ما

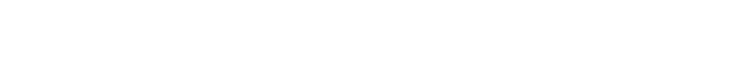

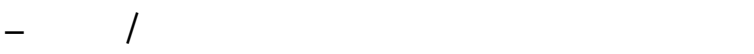

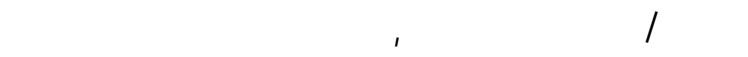

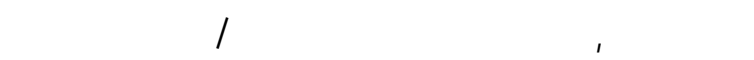

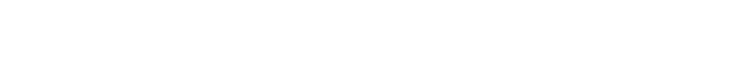

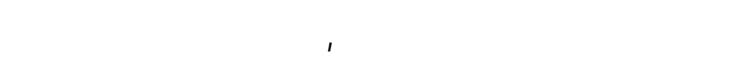

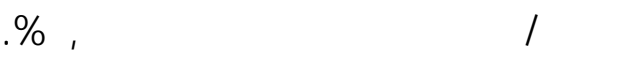

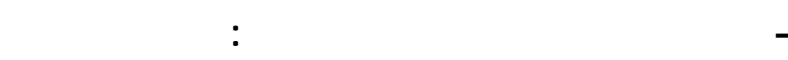

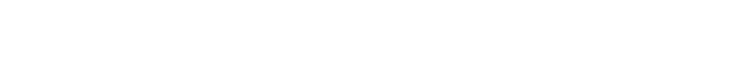

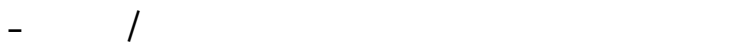

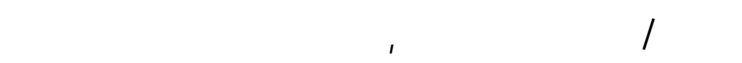

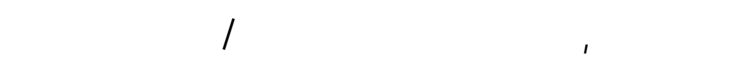

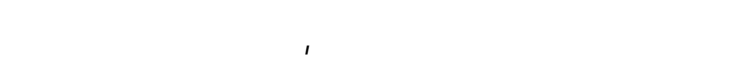

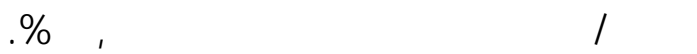
- تكالف الإنتاج: بلغ متوسط تك الف الإنت اج بال شرركة

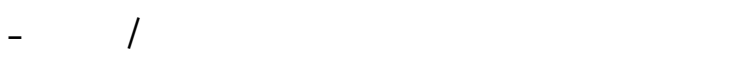

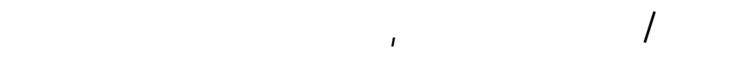

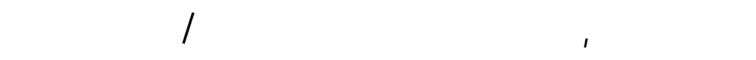

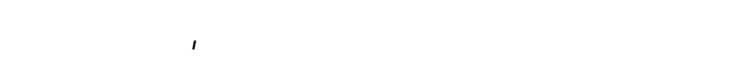

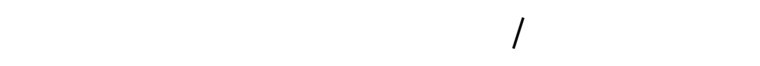
$\%$. $\wedge, 0$.

- تكالف النسوق: تُعتبر لحد المؤثر ـرات الت مي تعك س س حصة للثركة فى اللسوق من مظور العملاء من خللا

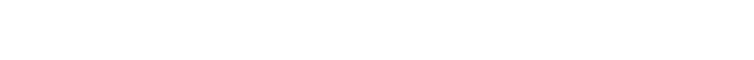

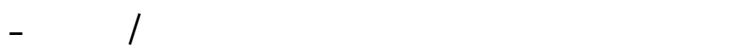

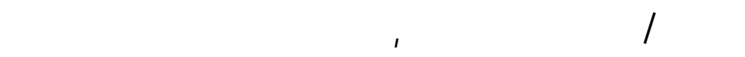

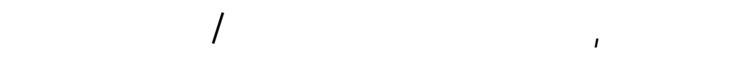
إتجهت للإنخفاض لتصل إلى حوالي 1,09 مليون جنيه

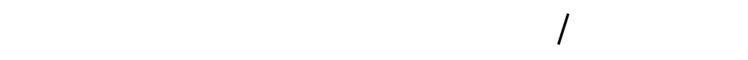




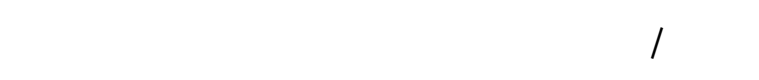

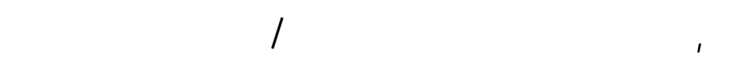

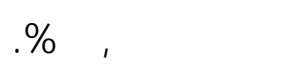

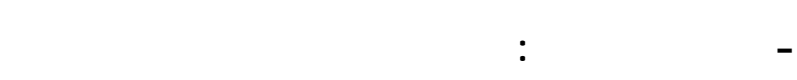

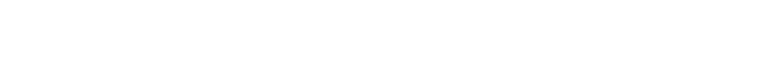

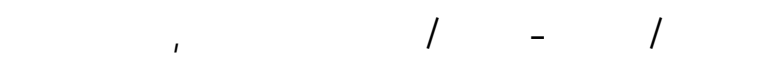

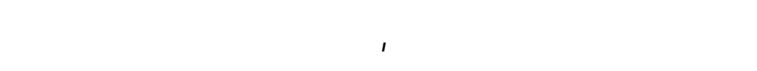

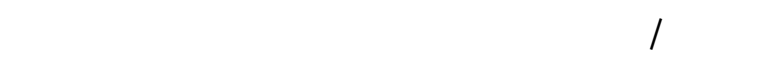

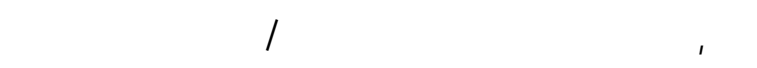

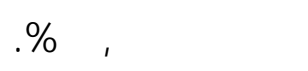

- إجمالي الأصطل: بلغ متوسط إجمالي الأصول بال شربكة

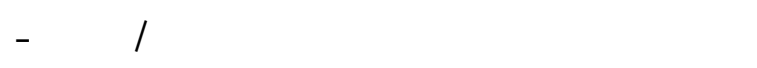

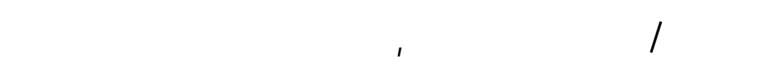
حوالي VT,

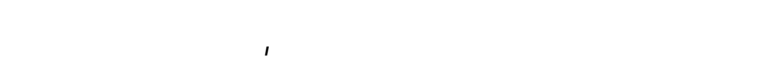

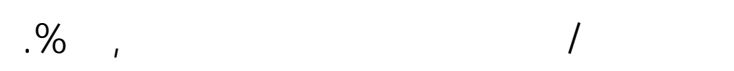
_ صلي جقوق المكية: بلغ متوط صافي حقوق الملكي ة

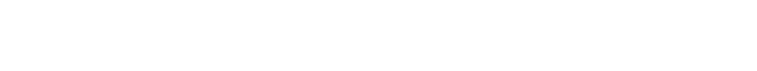
جا

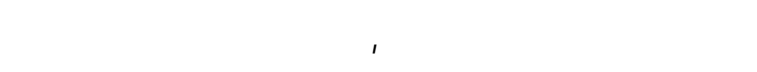

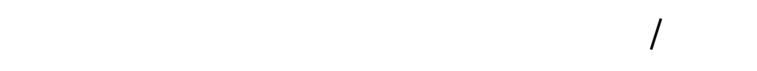

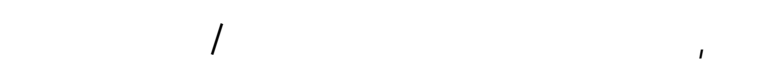

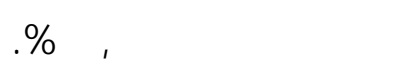

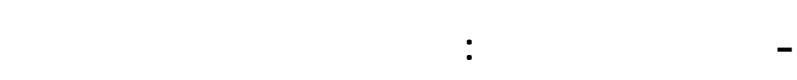

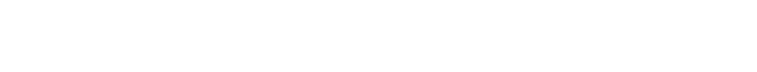

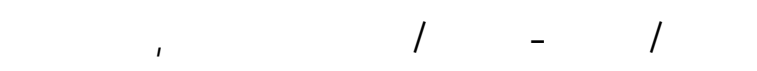

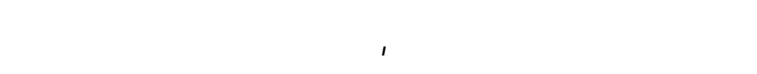

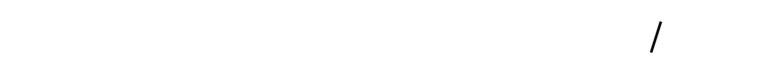

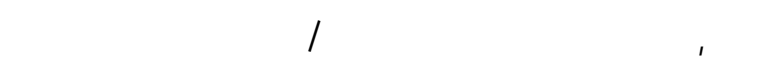

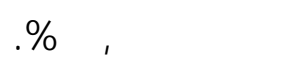

رلباً: أهم الملامح المالي ة التاربخي ة للا ششركة الهاه ة الصوالمع والنخزين:

يمكنا من خلال توصف البيانات المحلس ـبية الـ ـواردة

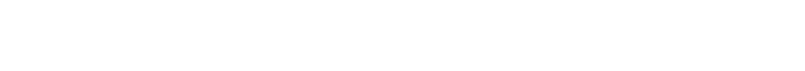

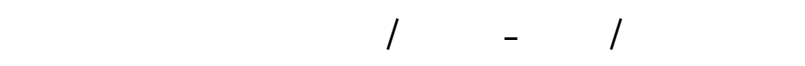

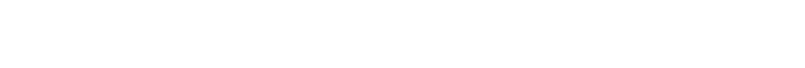
(0) على النحو التالي: -صلي الأصطل الثلبة: بلغ متوسط صافي الأصول الثابتة

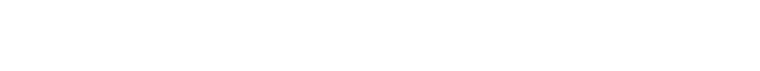

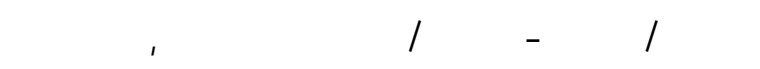

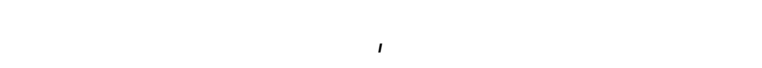

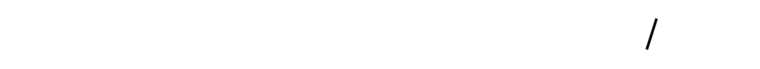

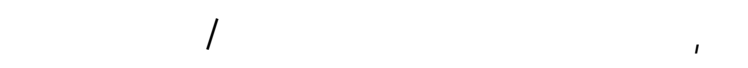

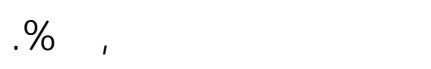

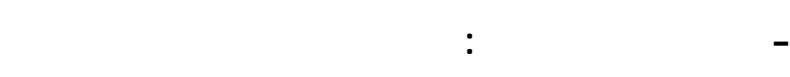

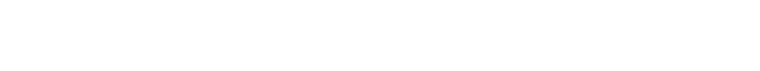

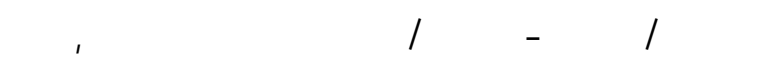

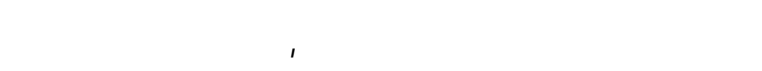

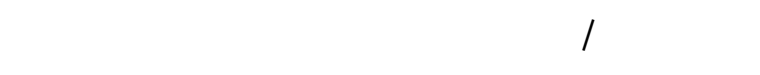

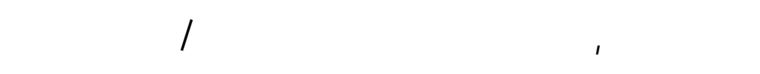

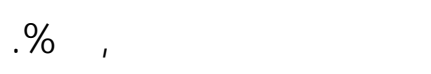
- المخزهن اللسلي: بلغ متوطط المخزون السلعي بللمركة

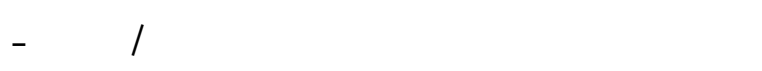

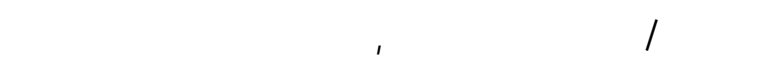

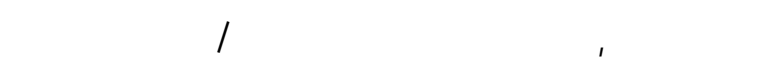
للإنخفاض ليصل إلى حوالي

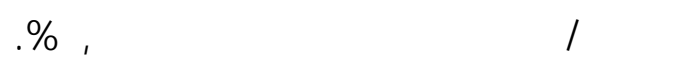

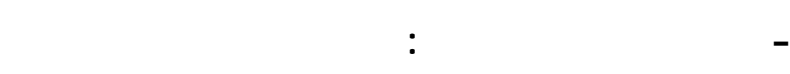

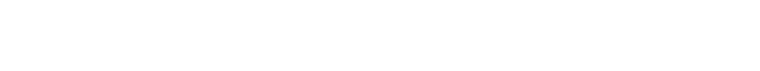

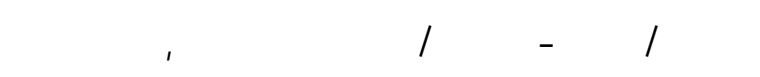

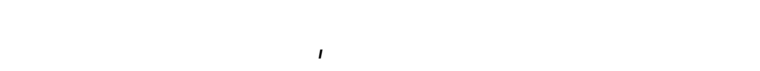




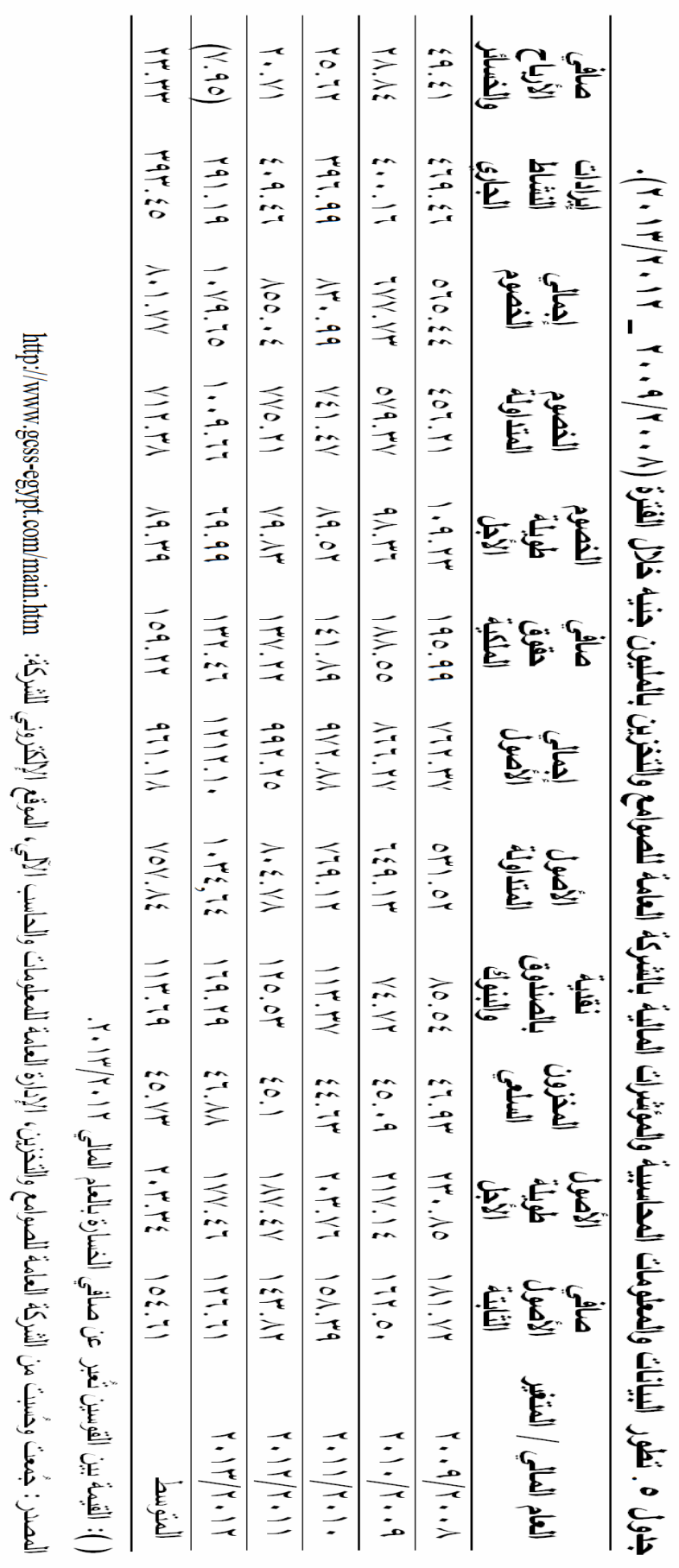


خلمساً: المعليير والمؤشرات المالية لقيم أذاء اللثركة اللامة لالصولمع والنخزني:

القد أثبتت البحوث الطبقية من خلل طورها التهائ التاريخي أن النب المالية لحد الأدوات الهلمة والفعالةس -واء في في في

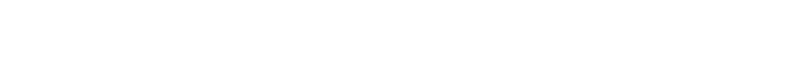

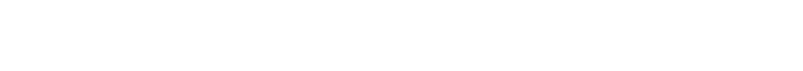

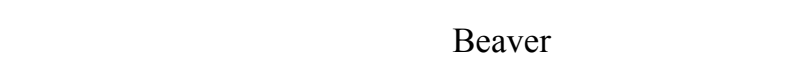

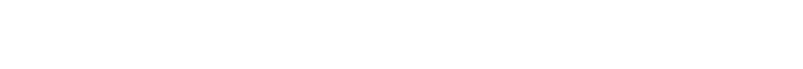

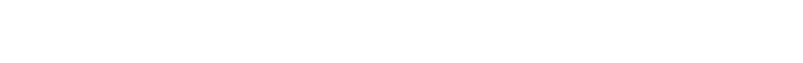

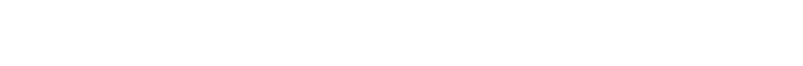
مؤثرات قيلس الجلب المالي بليستخدم النسب المالية.

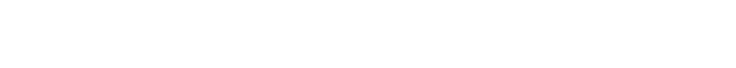

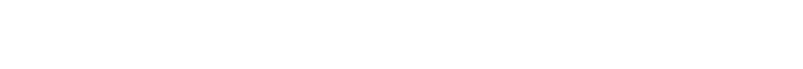

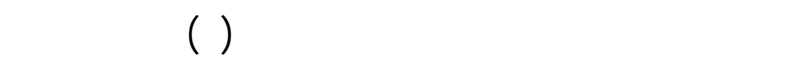

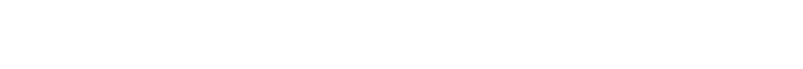

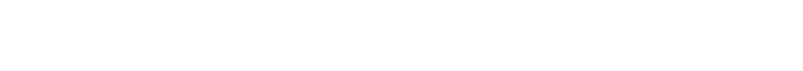

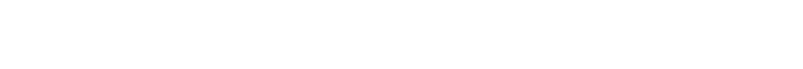

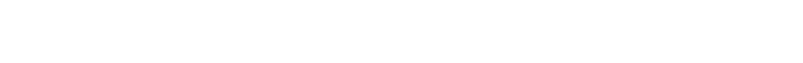

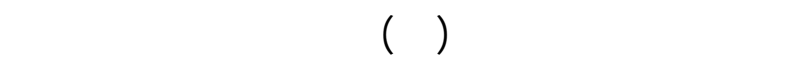

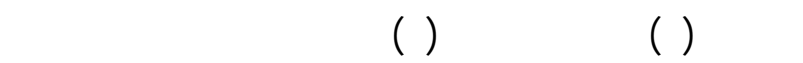

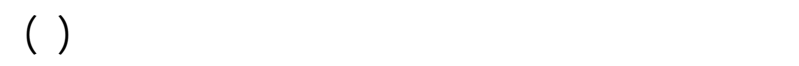

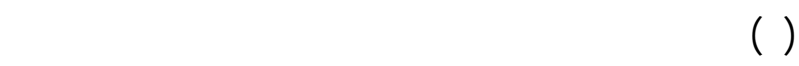

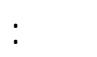

\section{مؤشرل نسب السيولة} - اللسبولة اللالية: توضضح مدى قدرة للثركة على الوفاء بإلتزاماتها في الأبل القصير حيث بلغت نسبة فئة اللسيولة العاية بللثركة العلمة للصوالمع والتخزين خلالل الفترة

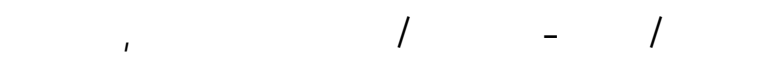

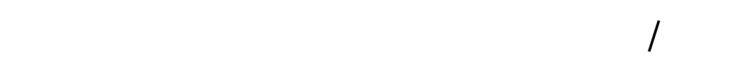

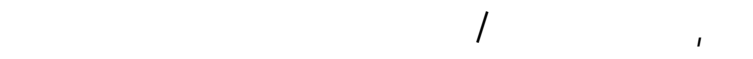
$.1, \cdot 1$
- الخصوم المتداولة: بلغ متوسط الخصوم المتداولة

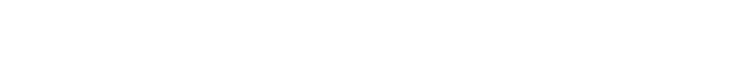

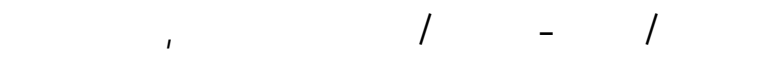

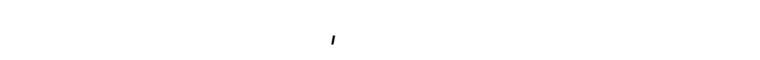

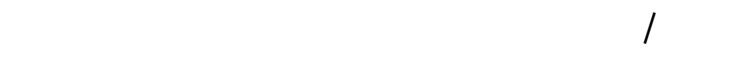

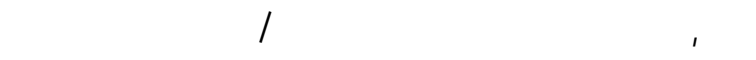

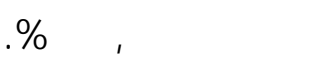
- إجمالل الخصوم: بلغ متوسط إجمالي الخصوم باللثركة

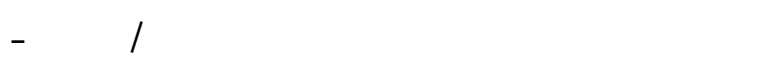

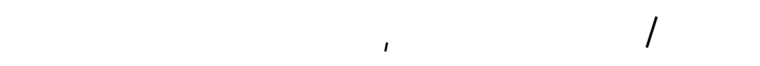

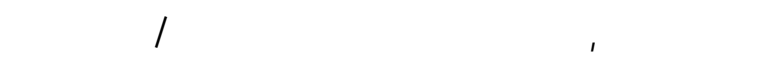

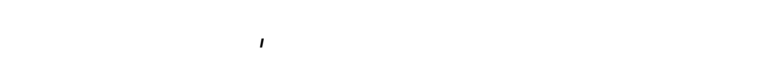

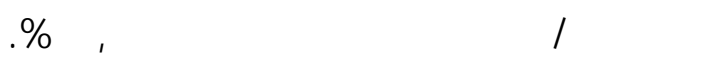

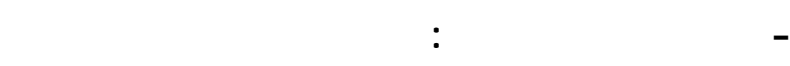

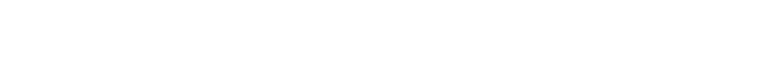

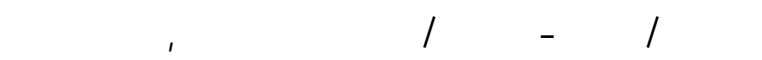

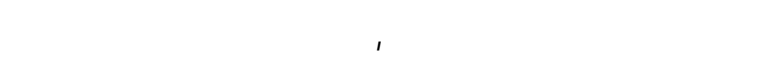

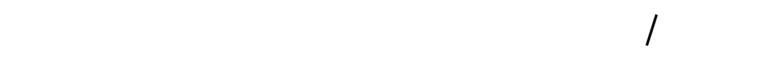

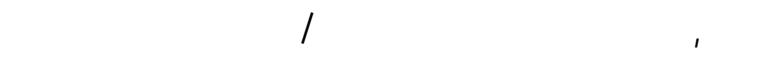
بلغت نحو \%YV,

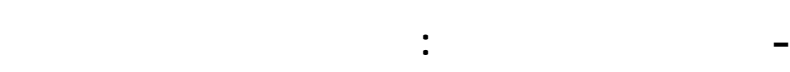

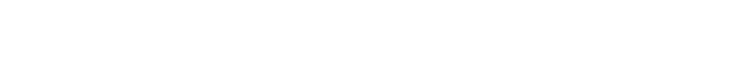

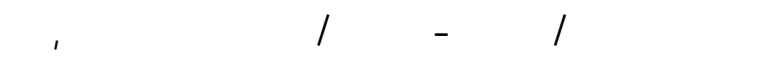

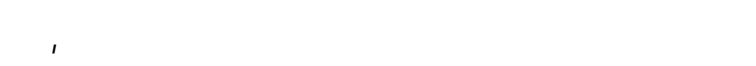

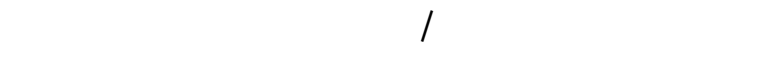

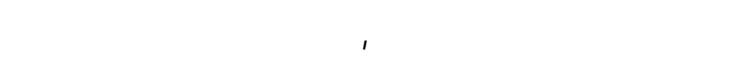

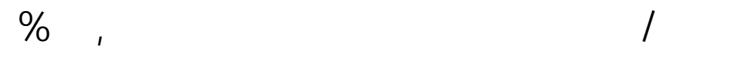

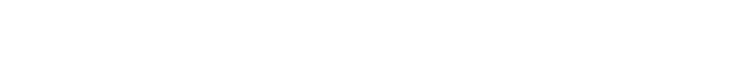
V, 90 


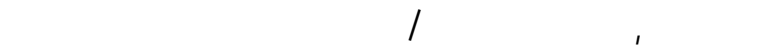

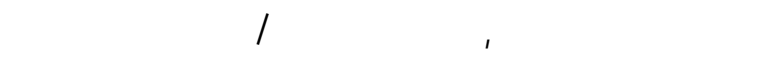

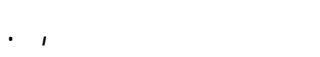

يتضح مماسق أن اللثركة تعاني م ـن ض عف الف الت ـرلمم الرئسمالي حيث أنمتوسط نسبة الأصول الثابتة الصفية

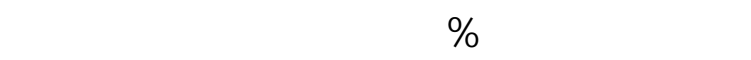

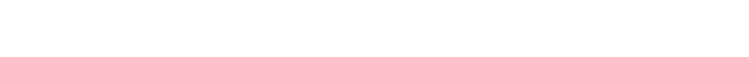
صحيح لمصادر التمويل المتلحة.

\section{مؤشرات نسب الهيكل التمويل}

-الخصوم قصيرة الألل/صلي هقوق المكية : بلغت نسبة

الخصوم قصيرة الأجل إل م ص الفي حق ـوق الملكي ـة

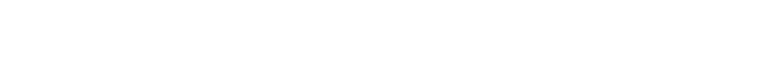
$\alpha$ ـ ـ ـ

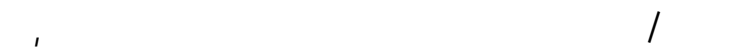

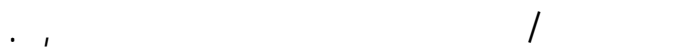
- الخصومطوبلة الألب/صلي حقوق المكية: بلغت نسبة الخصوهويلة الأجل إلى صافي حقوق الملكية بللثركة

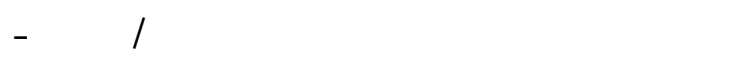

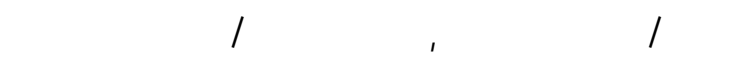

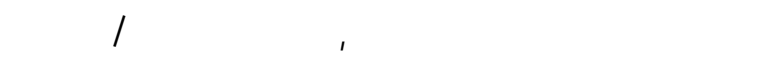
بمتوسطسنوي بلغ نحو 07, . . - إجمالي الخصوم/صلف גقوق الماكية: توض ح هـ ذه النبة مدى إمكانية تنطية إجمالي الخ صوم بليد تتخدلم صفي حقوق الملكية، وتعبر عن لأحدطرق قيلس الرفع المالي Leverage Ratios، حيث بلغ ت ن سبة إجم المي الخصوم إله صافي ح ق الملكي ـة بال شركة العلم

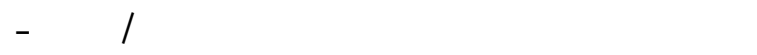

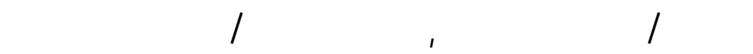

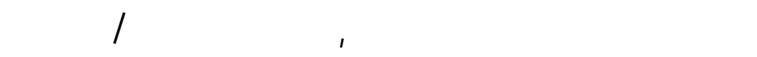
بمتوسطسنوي بلغ نحو عَץ 0, .
- اللسيولة السربهة: توضح مدى قدرة الثرركة على الوفاء

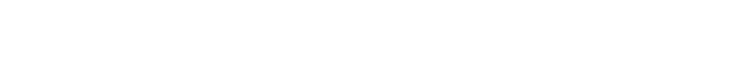
البضاعة، حيث بلغت نسبة للسيولة ال سرريعة بال ششركة

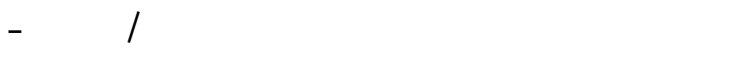
r.r.

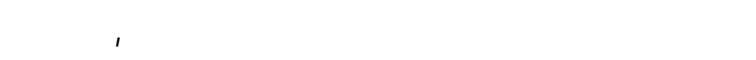

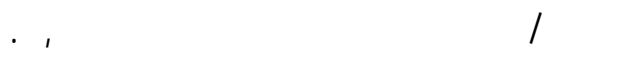
- اللسيولة القدية: بلغت نسبة السيولة القدي ـة بال شركة

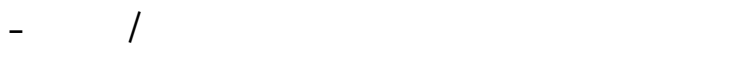
r.

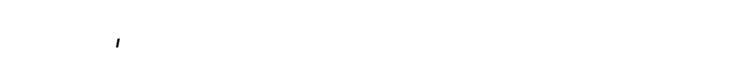

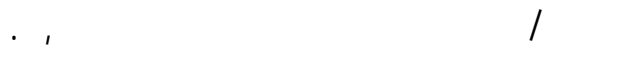
مماسبق يتضح أن الثركة العلمة للصوامع والتخ -زين

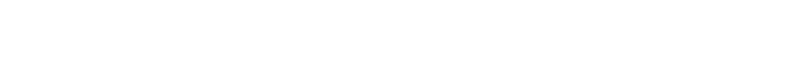

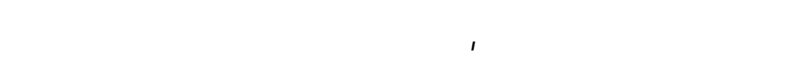

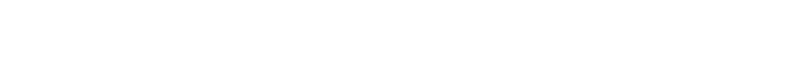

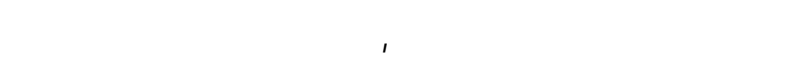

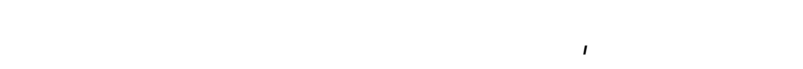
من تعثر مالي واضح، كما تعاني الثركة من مشكلة ترلكم

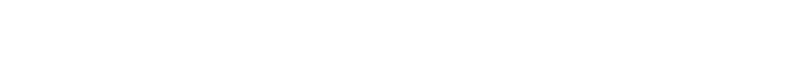

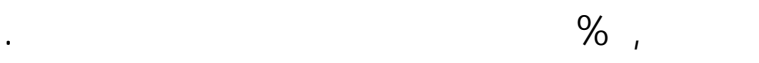

\section{مؤشرات نسب توازن هيكل الإستمار} - صالي الأصط الثالبتة/ إجمالي الأصطل: بلغت نسبة الأصول الثابتة الصفية في هيكل أصول اللثركة العلمة

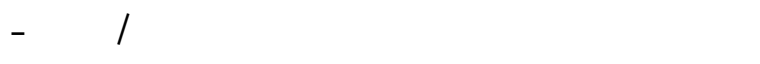

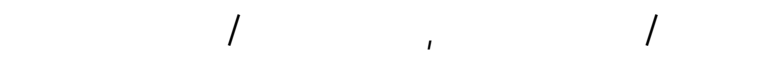
للإنخفاض لتصل إلى نحو · 1, بمتوسطسنوي بلغ نحو IV , IV - الأصطل المتداولة/ إجمالي الأصرل: بلغت نسبة الأصول

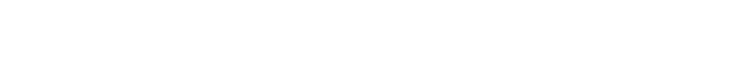

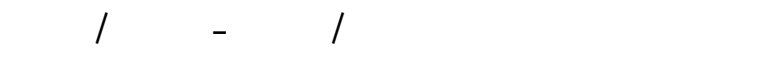


-لجمالل الخصوم/ إجمالل الأصطل: تُعبر هذه النسبة ء ـن إحدىطرق قيلس الرفع المالي Leverage Ratios. حيث المبن

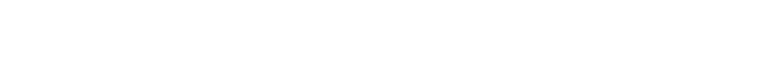

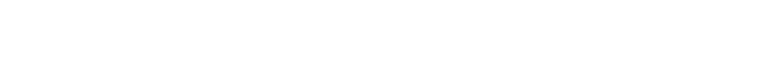

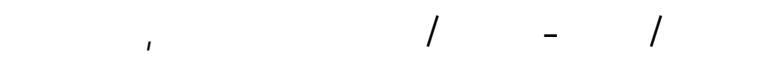

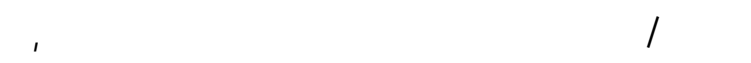

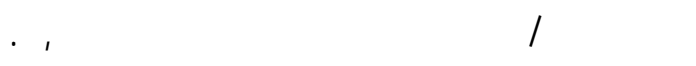

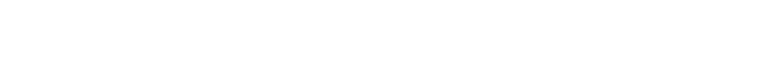

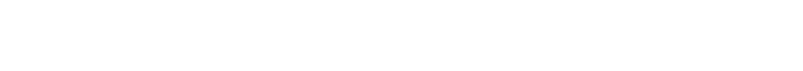

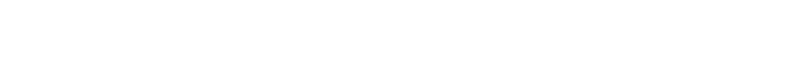

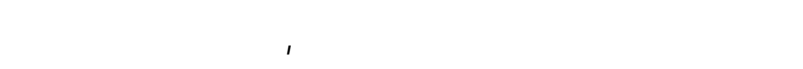

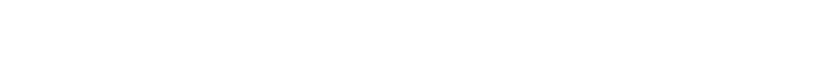
مصادر التموبل لخمة العمليك التشغيلية.

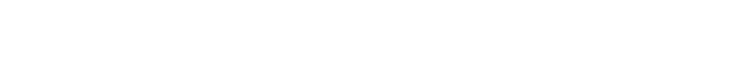

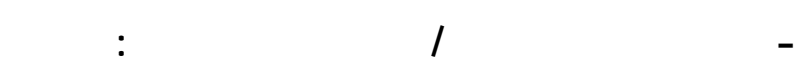
نسبة إيرادات الشطط الجاري إلى صالفي الأصول الثابل الثابنة

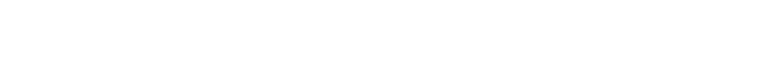

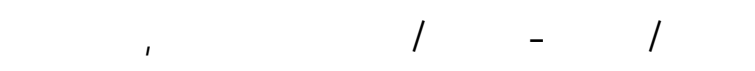

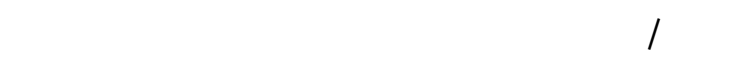

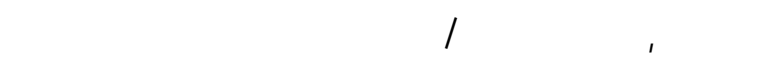
r,, $0 \varepsilon$

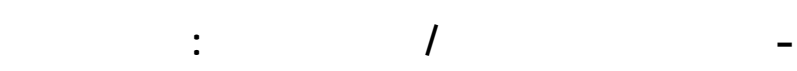

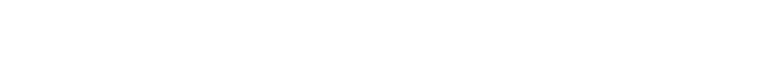

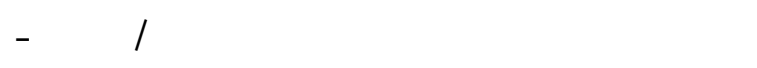

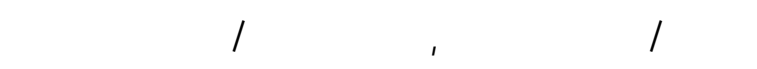

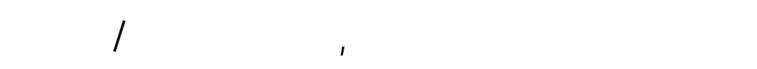
بمتوسطسنوي بلغ نحو بّع, . .

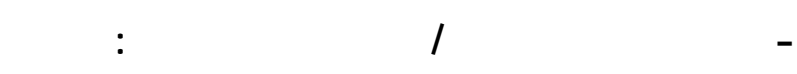

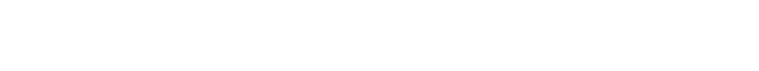

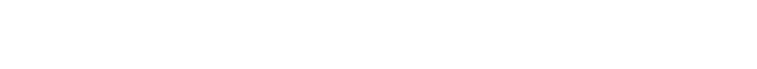

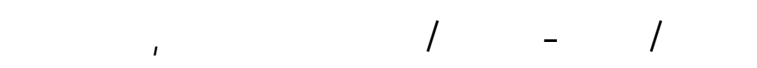

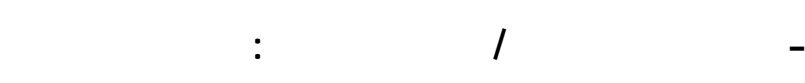

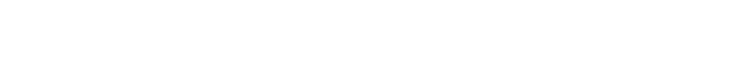

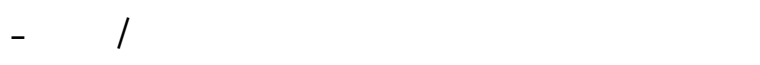

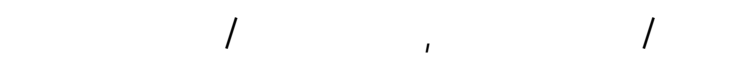

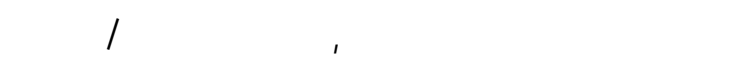

بمتوسطسنوي بلغ نحو بر ا, . .

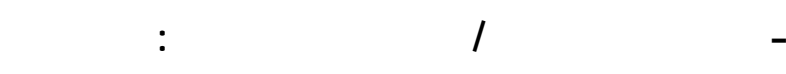

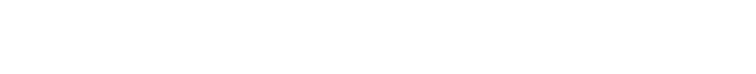

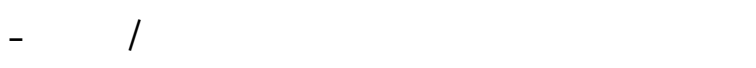

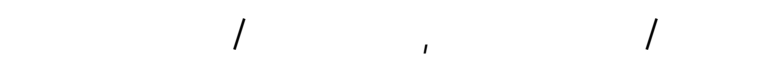

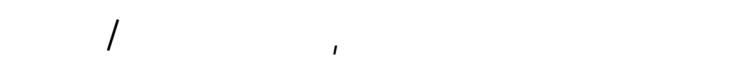
بمتوسطسنوي بلغ نحو 1,10.

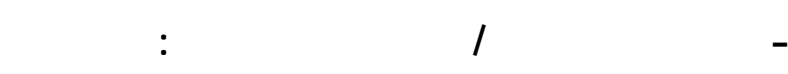
رلس المل المدفوع إلى صلفي الأصول الثابتة باللشركة

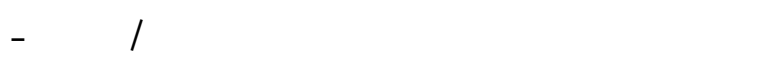

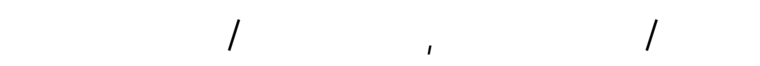

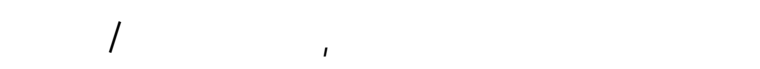
بمتوبطسنوي بلغ نحو ل17, ل.

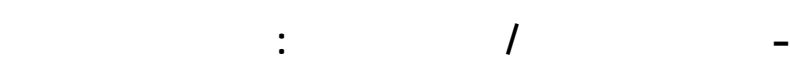

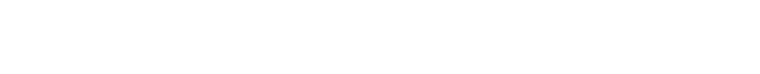

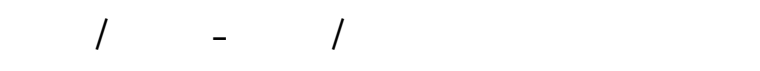

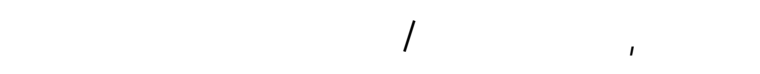
لتصل إلى نحو بر,

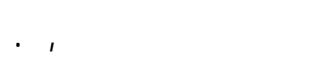

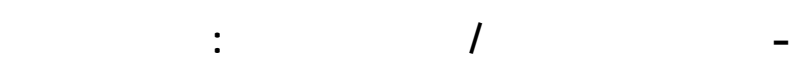

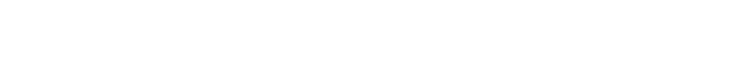

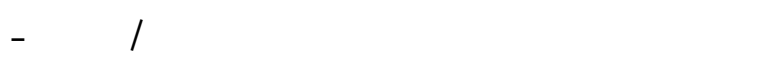

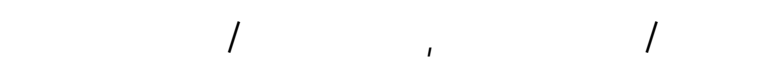

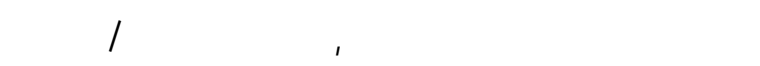
بمتوسطسنوي بلغ نحو · ا, ل. 


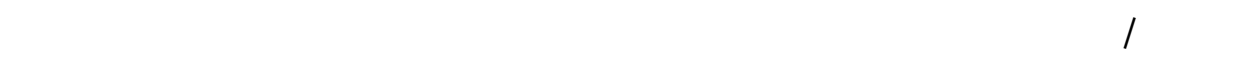

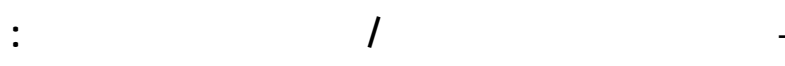
نحو ا

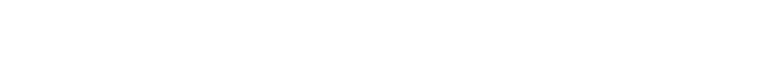
الشط الجاري باللثركة العلمة للصولمع والتخزين خللا

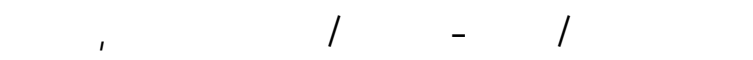

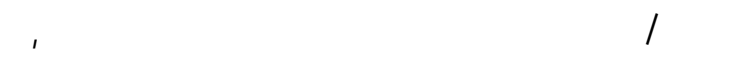

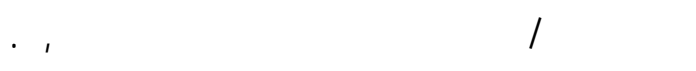

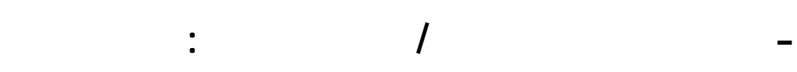
القدية بالصندوق والبنوك إلى إجمالي الأصول بللشرينة

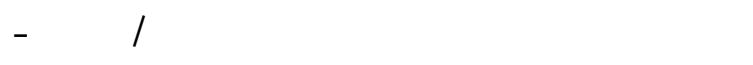

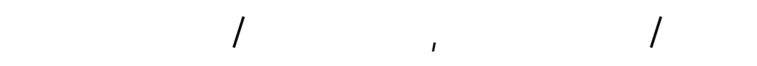

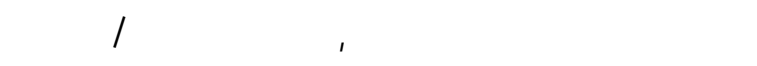
بمتوسطسنوي بلغ نحو بار إل.

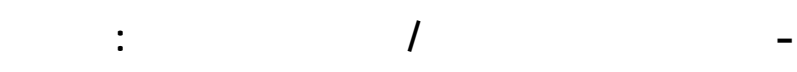

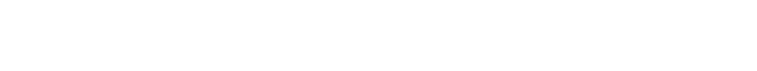

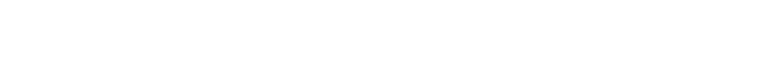

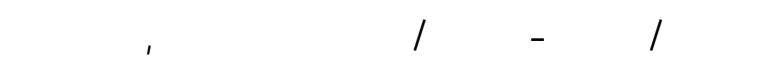

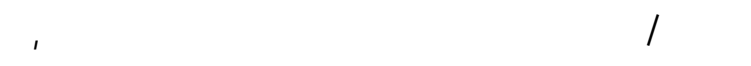

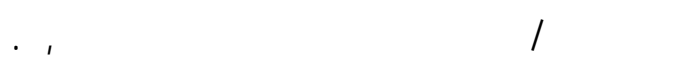

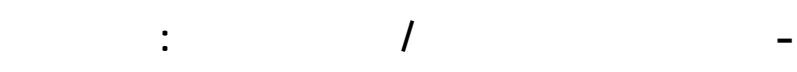

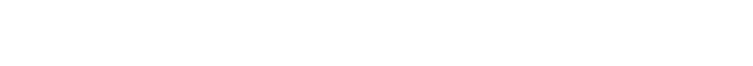

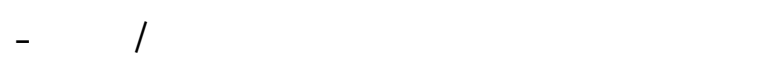

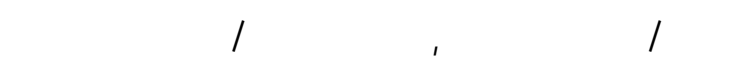

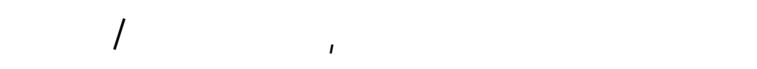
بمتوسطسنوي بلغ نحو عا, ل.

\section{مؤشرك القعرة الإيرالية للأصط المتداولة}

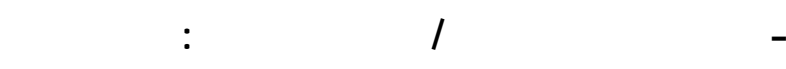

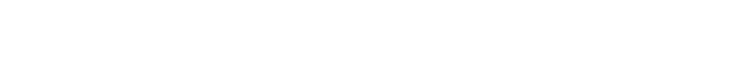

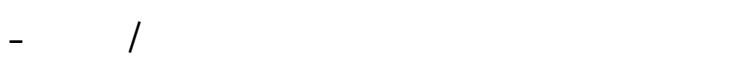

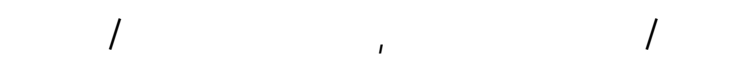

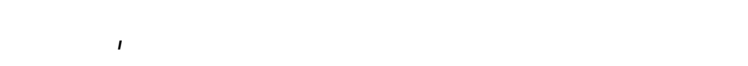

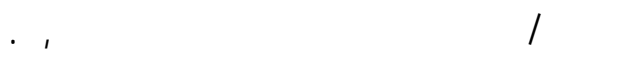

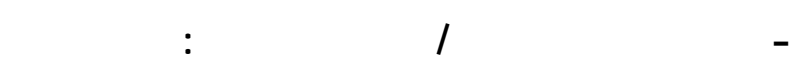

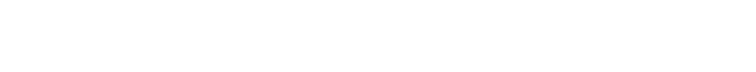

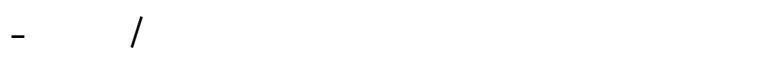

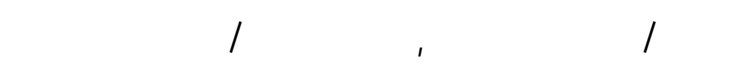

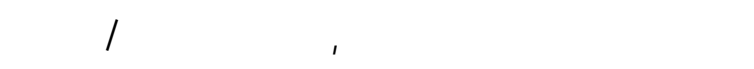

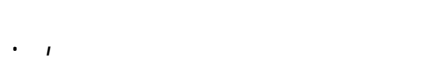
- إيرادل النشلا الجاري/ (لأصطل المتداولة - المخزهن

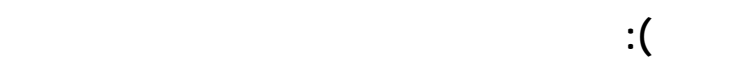
الأصول المتداولة مطروحا منها المخزون اللسلعي المبلي

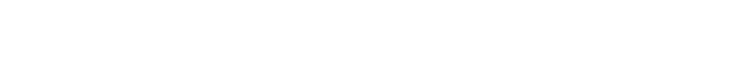

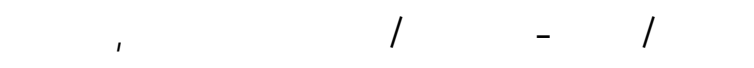

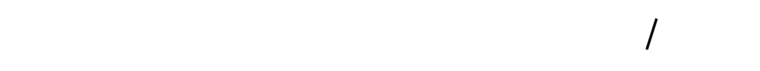

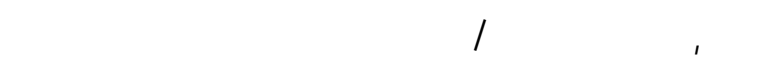
$\cdot, 7$.

\section{- إيرادل النطلا الجاري/ قدية بالصندو والبنكا:

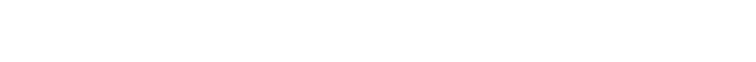 بالصندوق والبنوك بلالثركة العلمة للصوالمع والتخزين

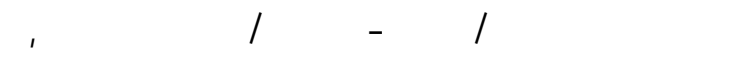

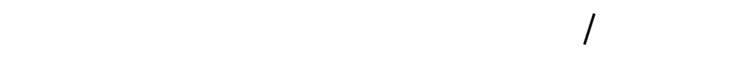

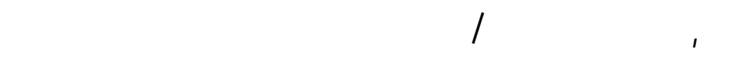
. 


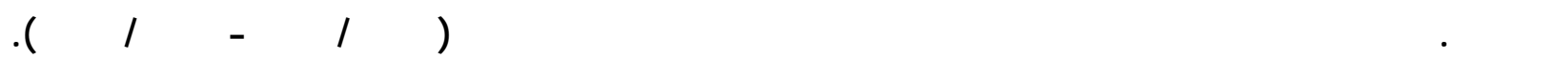

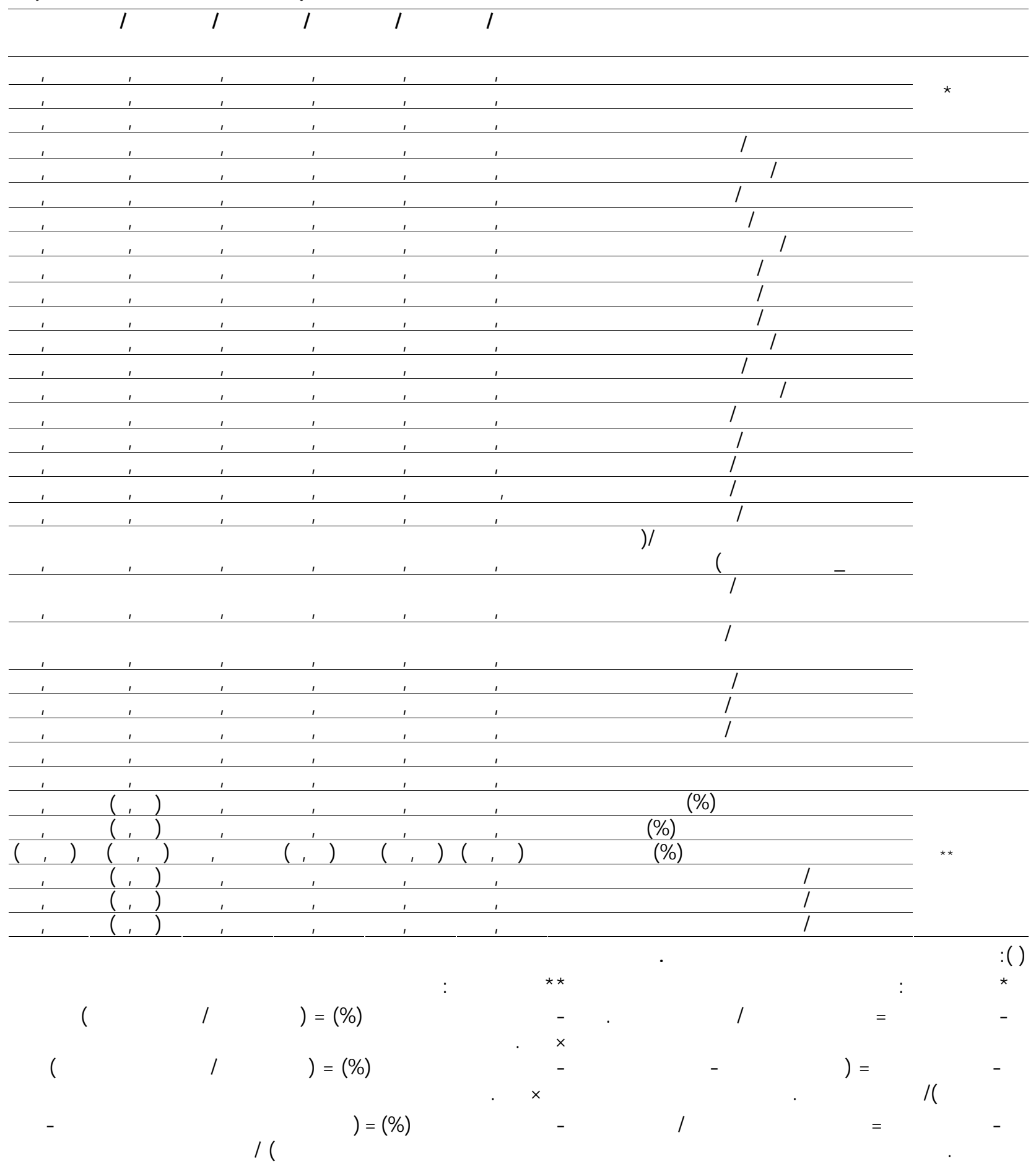

المصدر:جُمعت وُُسّبت من البيانت الوارة بجدولي (ع)، (0). 


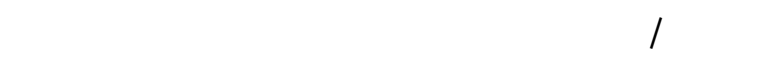

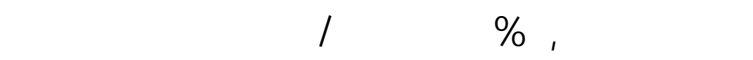

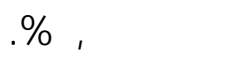
- العائد إلل صالي الأصط الثلبتة\%: بلغت ن سبة العائ د

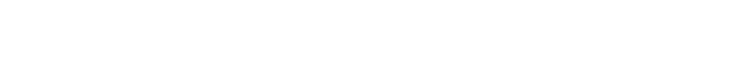

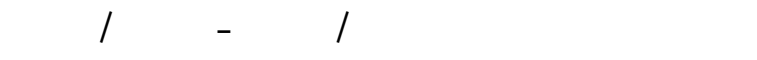

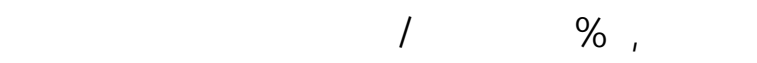

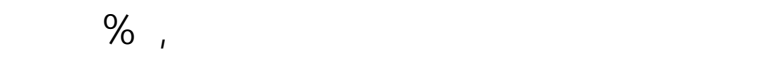

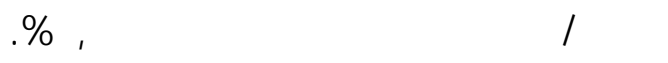
-مطل النمو ال عسنوي \%: يمكن التعبير عنها من خ لله

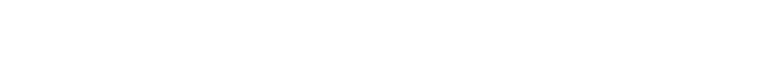

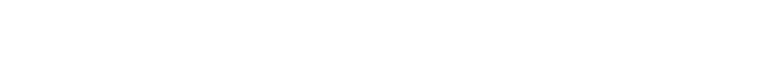
سجل هذا المعدل بللثربكة العلمة لل صولمع والتخ _زين

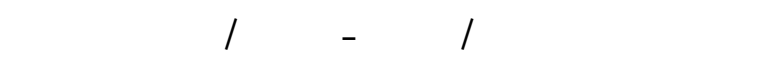

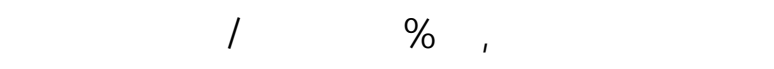

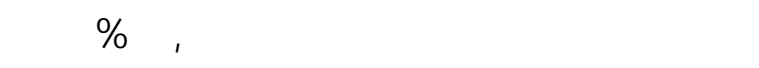

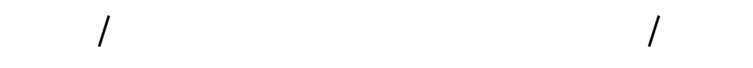

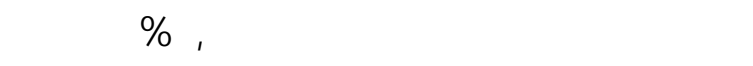
تناقصسنوي بلغ نحو 00, · 1 \% .

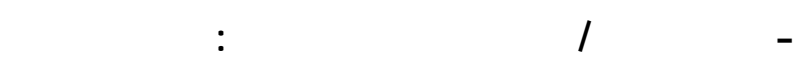
صافي الريح إلى إيرادات الذ ششط الج ارئ الري بال شرركة

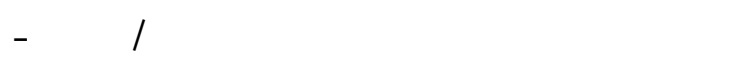

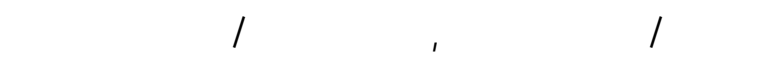

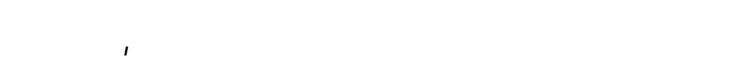

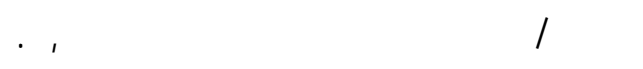
- صلي الريح/رلس المل المفوع: بلغت نسبة ص الفي

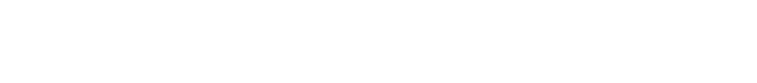

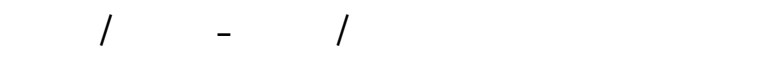

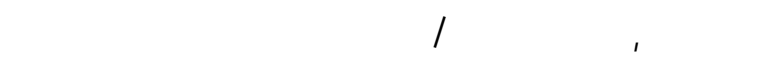

مما تم التوصل إليه من نتائج لمؤثرات نسب الت ـفقلت القدية يتضح أن للثركة العلمة للصولمع والتخزين تع اني الني

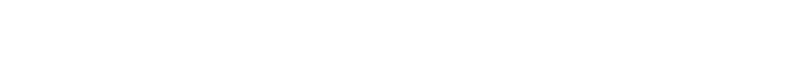

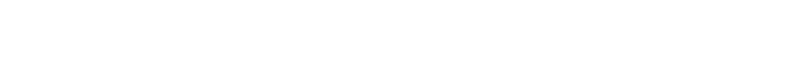

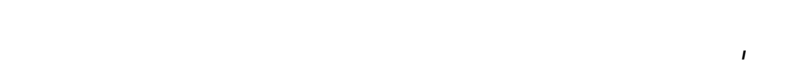

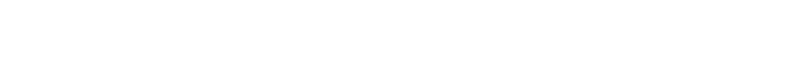
للفثل المالي، ويُستل على ذلك من خلل نسبة القدية إلى

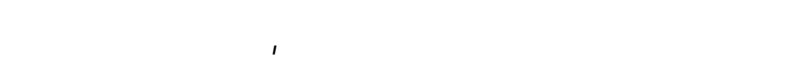

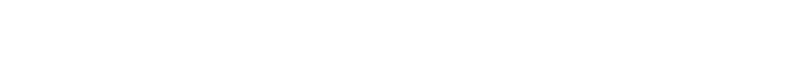

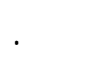

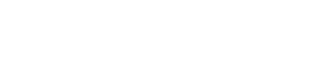

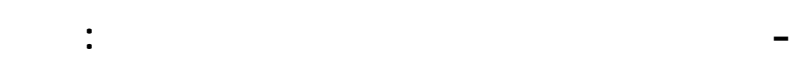

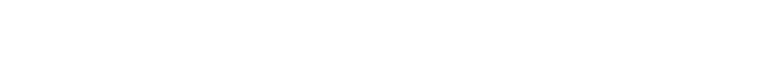

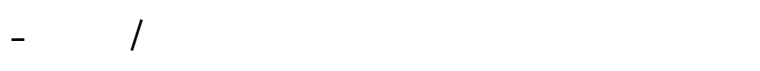

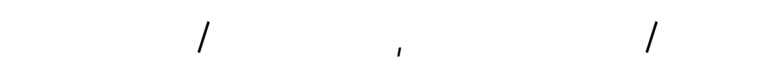

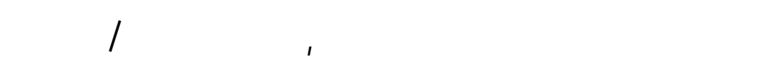
بمتوسطسنوي بلغ حوالي 0,97.

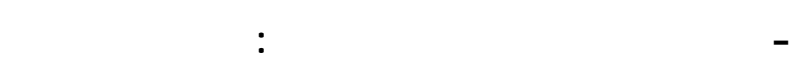

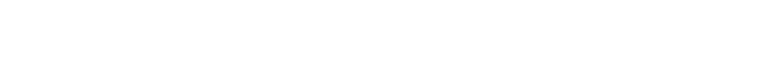

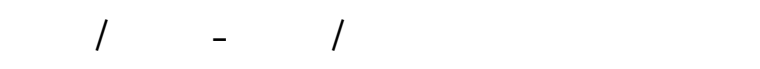

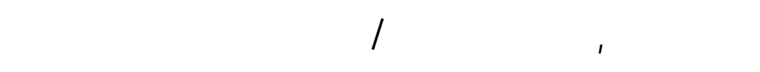

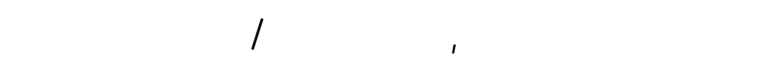

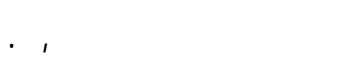
مؤشرك نسب الرسحية - الهائ إلل إجمالي الأصط \% \%

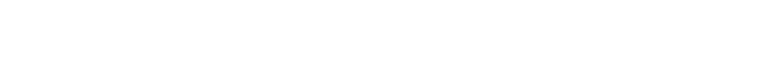

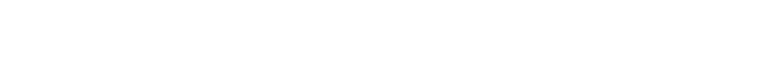

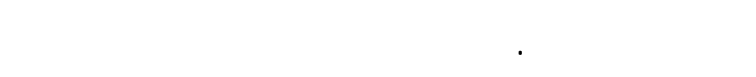
الأصول بللثركة العلمة للصولمع والتخزين خلال الفترة

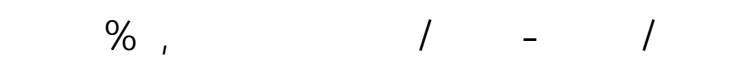




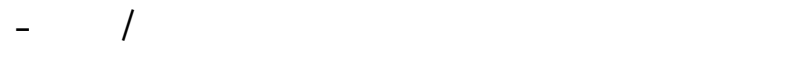

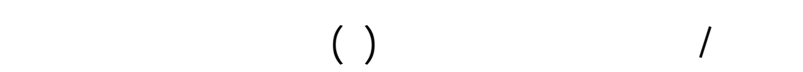
كبير في معلملات الإنحرف المعياري ومعلملات الإختلاف

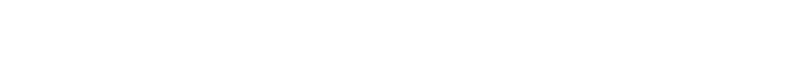

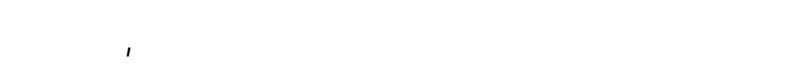

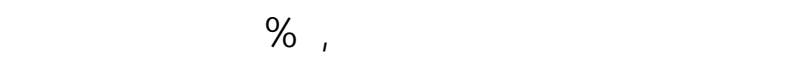
اللسلعي، ويصل إلى أقصى حد له المتغير الخصوم المتداولة

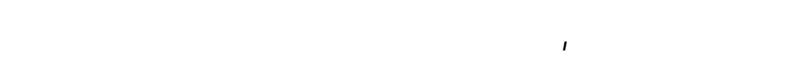

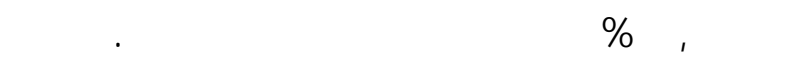

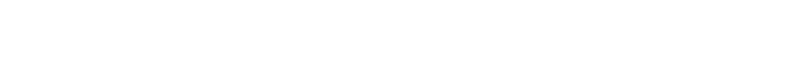

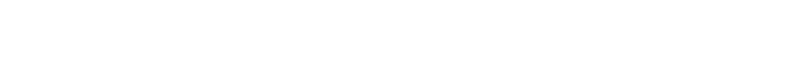

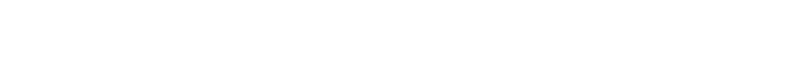

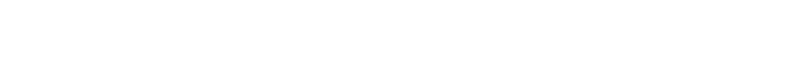

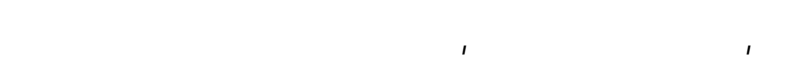

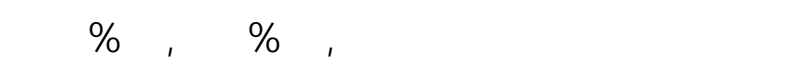
المتوطط على الترتيب، مما يعكس إرتفاع درجة المخطارة الكلية اللثركة.

\section{قيلس الإرتبلا بين متغيرات الموذج المالل}

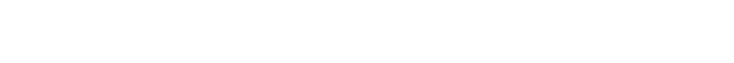

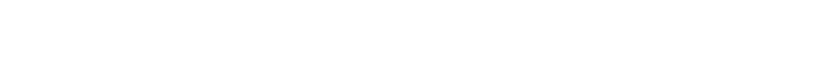

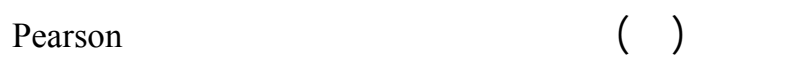
| خ _ Correlation

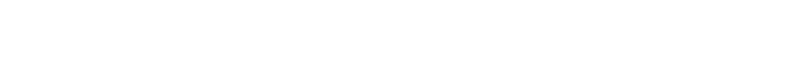

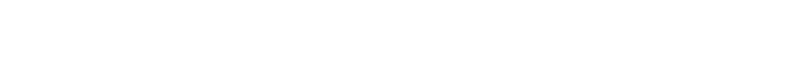

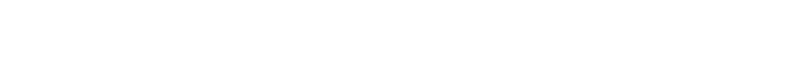

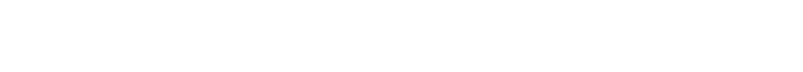

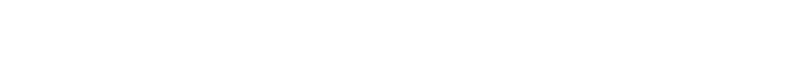

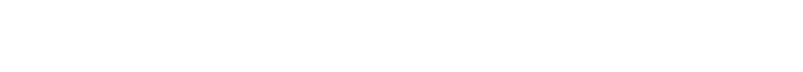

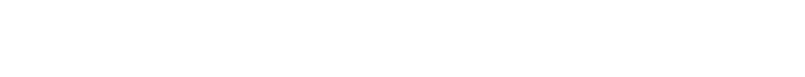

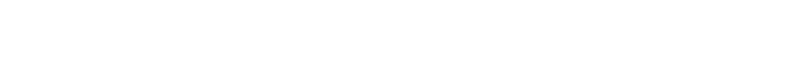

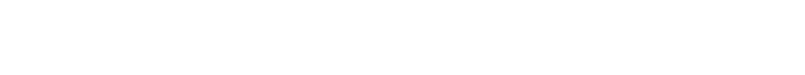

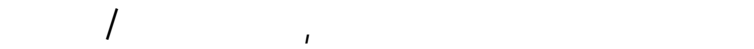
بمتوسطسنوي بلغ نحو سبر, . .

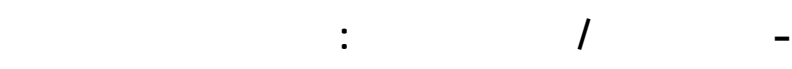
إلى إجمالي الخصوم بالثرركة العلمة اللصوالمع والنخزين

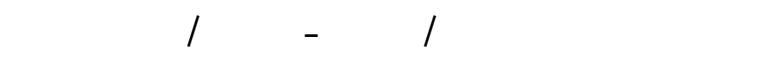

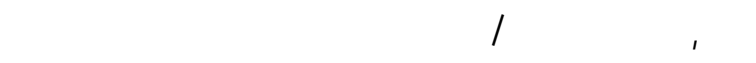

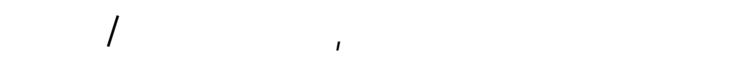

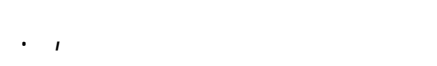

\section{مؤشرات قيلس الإسقرار والمخللرة}

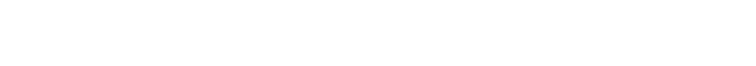

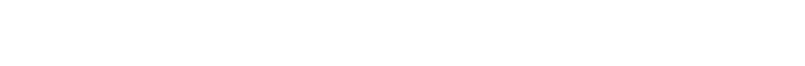

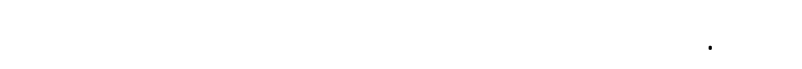

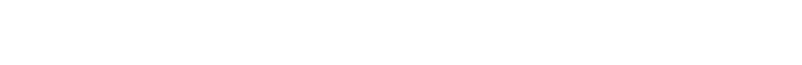

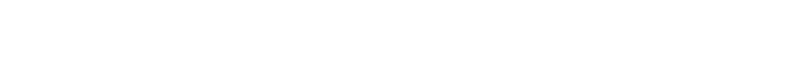

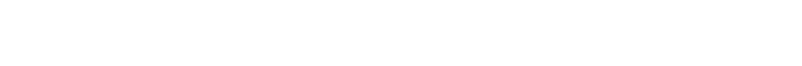
الإنحراف المعياري لمعدلات العائد مساوياً للصفر فالن هذا

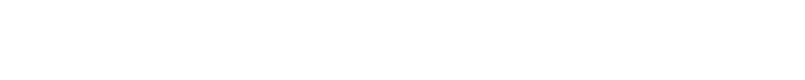
هisk Free Asset

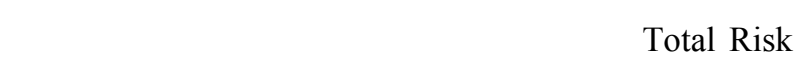

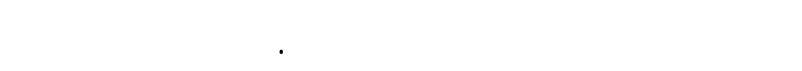

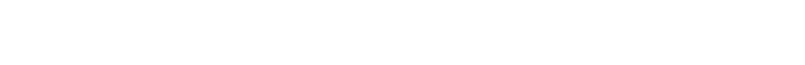

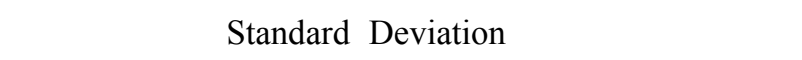

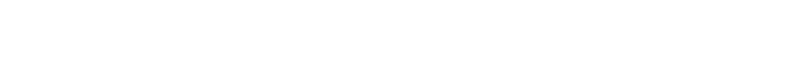
Cofficient of Variance (CV)

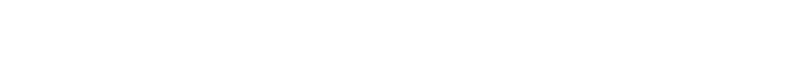

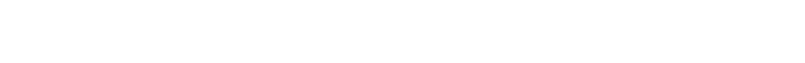

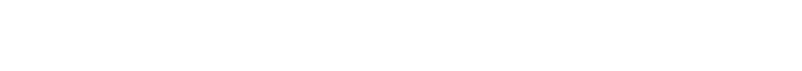
الإحتمالي المتوقع، بينما يعتمد الإبلوب الثاني على البيانات التاريخية.

بليستعراض معلملات الإنحرف المعياري ومع لملات المات الإختلاف للبيانات والمؤشرات المالي هة بال شرركة العله 
كما تبين أن هناك عدد من المتغيرات ترتبط ببع ضضها إرتبط طردي ضغعف حيث تراوح معلط الإرتبط المفر

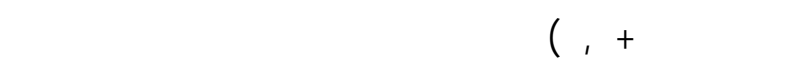

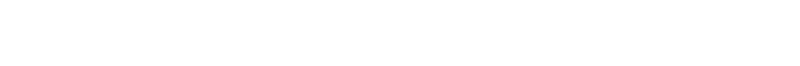

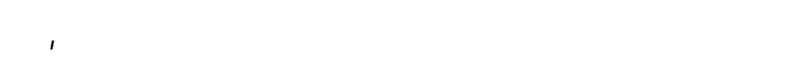

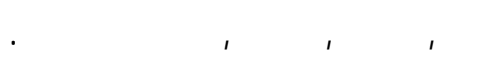

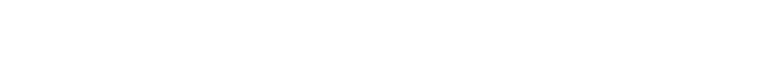

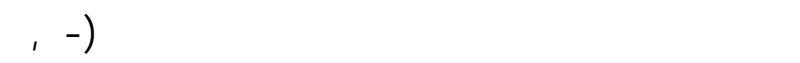

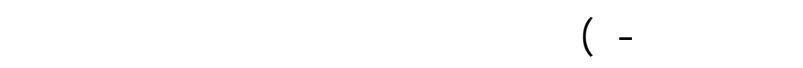

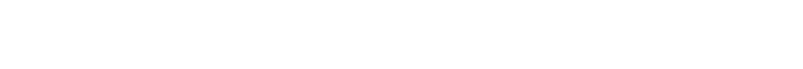

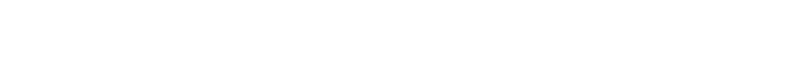

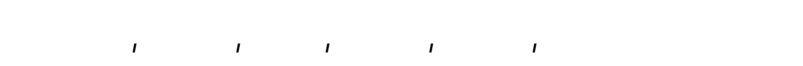

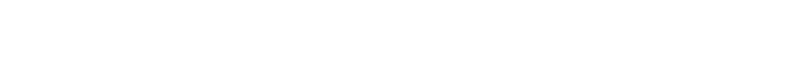

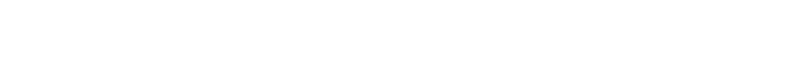
والنسارة ، إيرادات الشطا الجاري إذب بلغ معالمل الإرتبطا

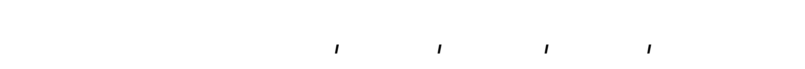

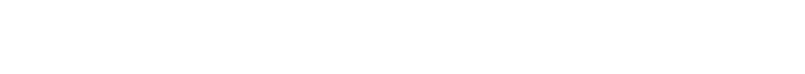

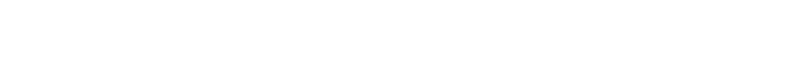

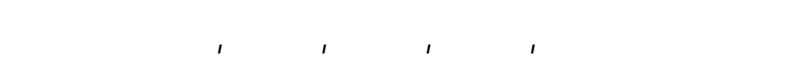

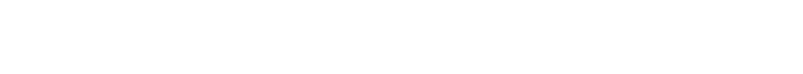

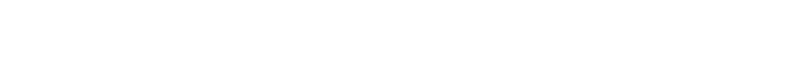

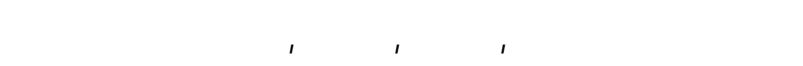

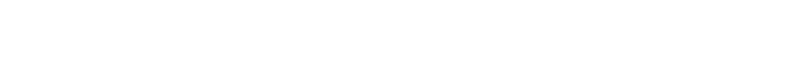

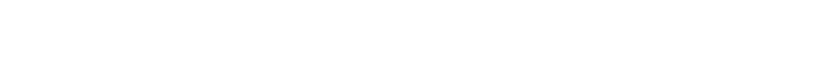

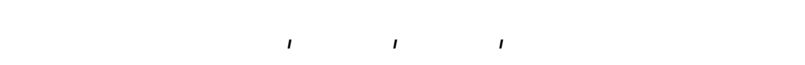

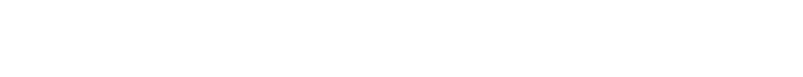

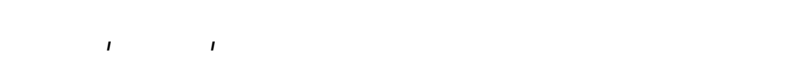

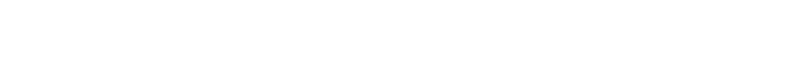

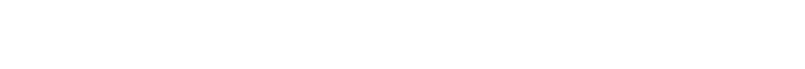
حوالي 9V , ، ، זو, · على الترتيب،
الدلالات الإحصائية ذات المفعة في إتخاذ بعض الق _رارات

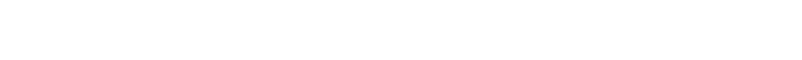
مصفوفة الإرتبط بين متغيرات النموذج المالي، وال ـواردة

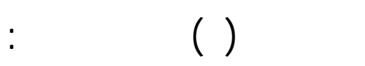

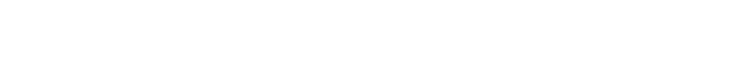

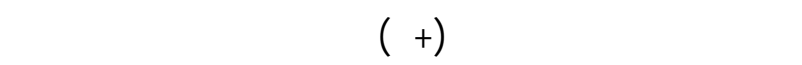

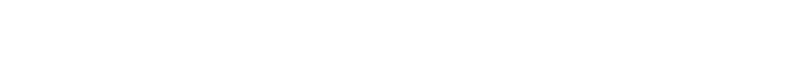

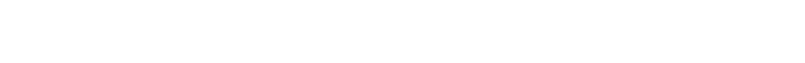
من الخصوم المتداولة وإجمالي الخصوم.

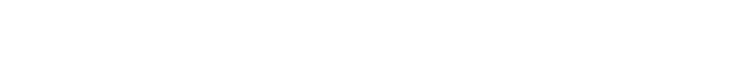

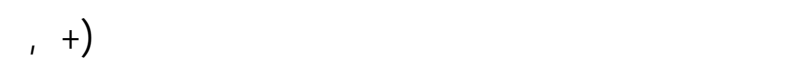

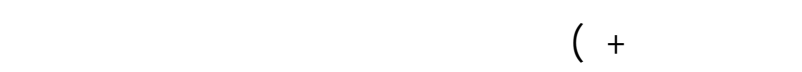

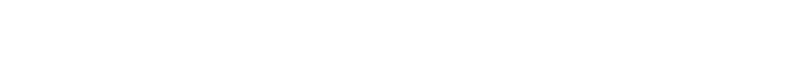

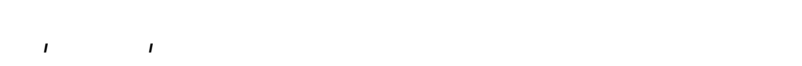

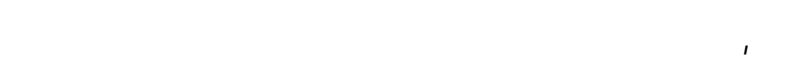

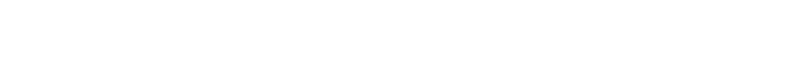

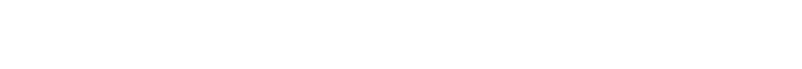

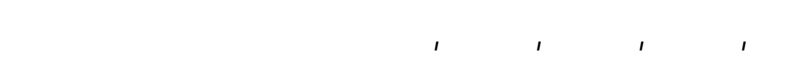
الأصول الثابة ولم من الخصوم طويلة الأج لـ، صـ الفي

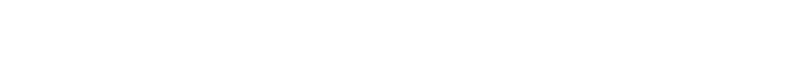

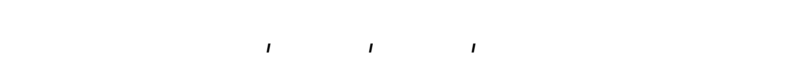

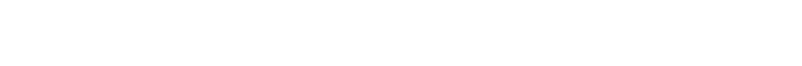

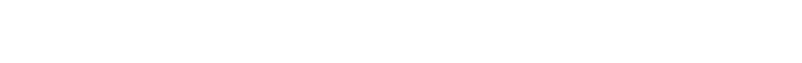

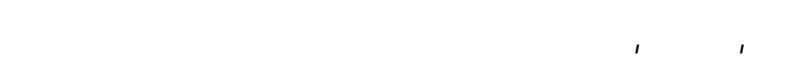

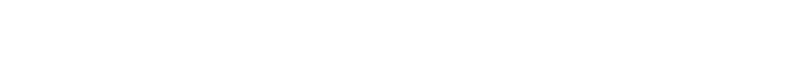
حوالي 91 ، . . كما تبين أن هنك متغيرين يرتبطان ببعضهما إرتب لطال

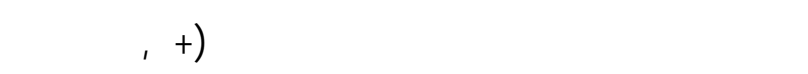

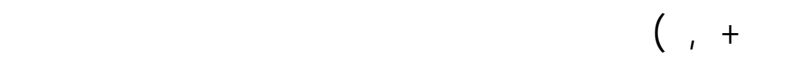
والتمويلية إذ بلغ معالل الإرتبط حوالي 


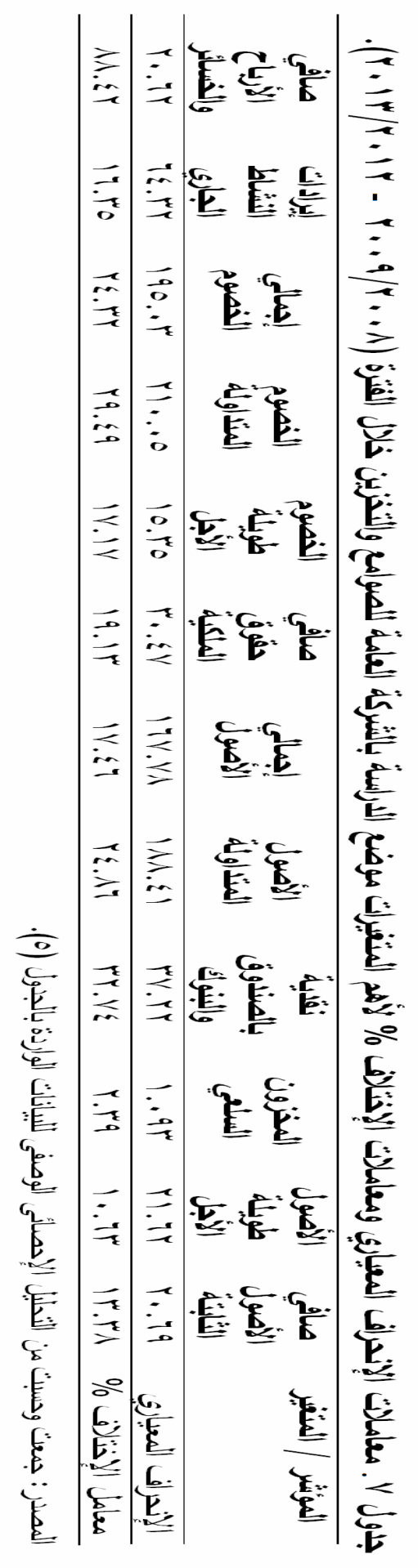




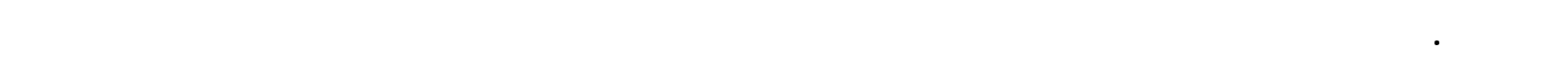
$(r \cdot 1 r / r \cdot 1 r-r+.9 / r \cdot \Lambda)$

\begin{tabular}{|c|c|c|c|c|c|c|c|c|c|c|c|}
\hline $\mathrm{x} 11$ & $\mathbf{x 1 0}$ & x9 & x8 & $\mathbf{x} 7$ & x6 & $\mathrm{x5}$ & $\mathrm{x4}$ & $\mathrm{x3}$ & $\mathrm{x2}$ & $\mathbf{x 1}$ & المتغير \\
\hline$\cdot, 91$ & $1, \cdots$ & $(\cdot, 9 \Upsilon)$ & $(\cdot, 9 \Upsilon)$ & $\cdot, \Lambda \mathrm{V}$ & $(\cdot, 90)$ & $(\cdot, ૧ દ)$ & $\cdot 91$ & $(\cdot, \Lambda \mathrm{V})$ & $(\cdot, \cdot Y)$ & $1, \cdots$ & $\mathrm{x} 1$ \\
\hline$(\cdot, \Gamma Y)$ & $(\cdot, \cdot 1)$ & $\cdot, \mathrm{NO}$ & $\cdot, \mu\rceil$ & $(\cdot, 01)$ & $\cdot, r q$ & - & $\left(\cdot, \varepsilon{ }^{\mu}\right)$ & $\cdot, \varepsilon 0$ & $1, \cdots$ & & $\mathrm{x2}$ \\
\hline$\left(\cdot, १^{\mu}\right)$ & $(\cdot, \wedge 0)$ & $\cdot, 91$ & $\cdot, 91$ & $(\cdot, 9 \Lambda)$ & $\cdot, 9 \mathrm{~V}$ & $\cdot, 9 \mathrm{~V}$ & $(\cdot, 97)$ & $1, \cdots$ & & & $\mathrm{x3}$ \\
\hline$\cdot, 9 \mathrm{~V}$ & $\cdot, 91$ & $(\cdot, 9 \mathrm{~V})$ & $(\cdot, 9 \mathrm{~V})$ & $\cdot, 99$ & $(\cdot, 9 \mathrm{~V})$ & $(\cdot, 9 \Lambda)$ & $1, \cdots$ & & & & $\mathrm{x4}$ \\
\hline$(\cdot, 9 \Lambda)$ & $(\cdot, ૧ \varepsilon)$ & $1, \cdots$ & $1, \cdots$ & $(\cdot, 9 \Lambda)$ & $1, \cdots$ & $1, \cdots$ & & & & & $\mathrm{x5}$ \\
\hline$(\cdot, 9 \Lambda)$ & $(\cdot, 90)$ & $1, \cdots$ & $1, \cdots$ & $(\cdot, 9 \mathrm{~V})$ & $1, \cdots$ & & & & & & x6 \\
\hline$\cdot, 90$ & $\cdot, \Lambda 7$ & $(\cdot, 9 \Lambda)$ & $(\cdot, 9 \Lambda)$ & $1, \cdots$ & & & & & & & $\mathbf{x} 7$ \\
\hline$(\cdot, 9 \mathrm{~V})$ & $(\cdot, 9 \pi)$ & $1, \cdots$ & $1, \cdots$ & & & & & & & & $\mathrm{x8}$ \\
\hline$(\cdot, 9 \mathrm{~V})$ & $(\cdot, 9 \%)$ & $1, \cdots$ & & & & & & & & & x9 \\
\hline$\cdot, 91$ & $1, \cdots$ & & & & & & & & & & $\mathbf{x 1 0}$ \\
\hline $1, \cdots$ & & & & & & & & & & & x11 \\
\hline
\end{tabular}

\begin{tabular}{|c|c|}
\hline الخصوطويلة الأجل & $: \times 7$ \\
\hline الخصوم المتداولة . & :x \\
\hline إججمالي الخصوم. & \\
\hline صايفي الريح والنشارة الجاري . & : \\
\hline
\end{tabular}
حيث تُمل

المصدر:جُمعت ومُسبت من التحليل الإحصائي الوصفي للبيانت الوارةة بجدولي (ع)، (0).

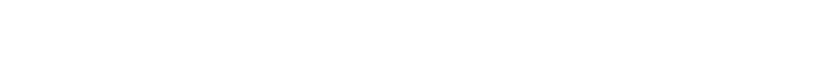

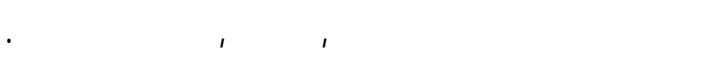

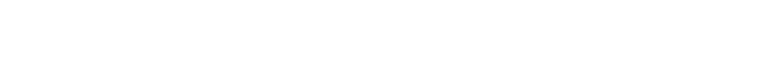
بهزه النب المالية في إجراء التك ـوين المذ الي لأص ـولها

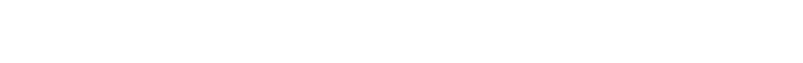
الإرتبط للساق عرضها بين كل من الفق لت والإي _رادات

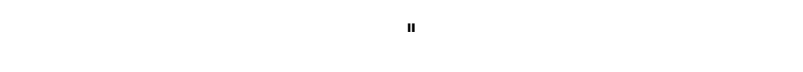

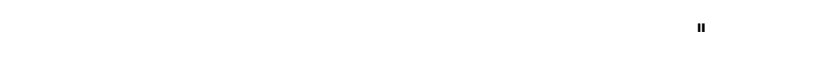
إتجاهلت الترالط بين بذ -ود التك اليف وبذ _ود الإي _رادات والأصول والخصوم كما أن التحليل المالي (بالنب النمب المالية)

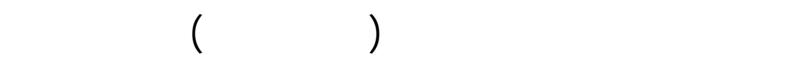
المالية بين البنود المحلسبية المختلفة ولمستخلاص المع الفي لئية

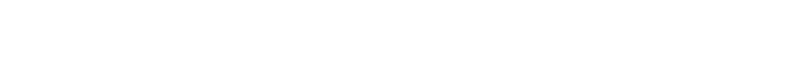

وإجمالي الخصوم ومل من صافي الريح والنسارة، إيرادات

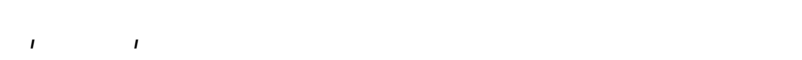

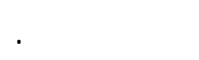
كما تبين أن هنك عدد من المتغيرات ترتبط ببع مضها

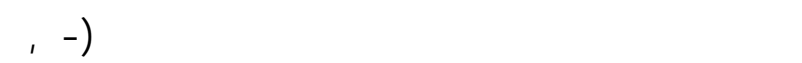

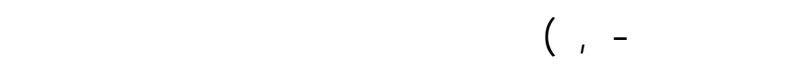

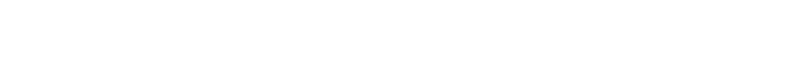
حوالي 01, ، ، سع, · على الترتيب.

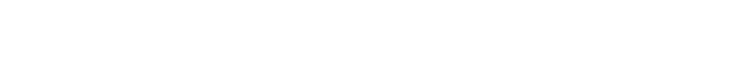

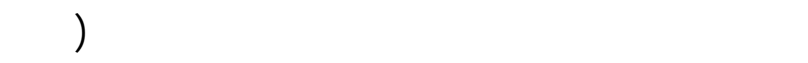

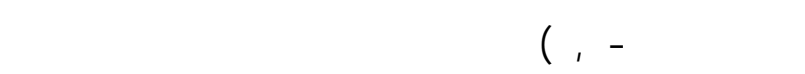

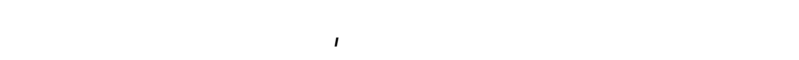


عسين عا غنيم (1999) ): درلسك في التمول، الطبعة الأوله،

القاهرة .

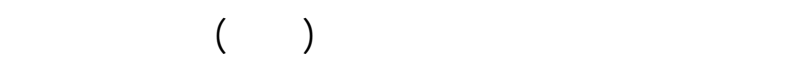

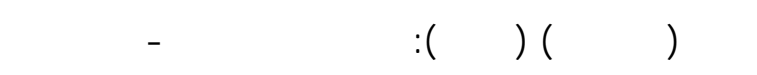

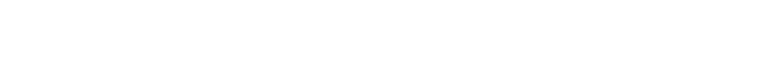

للنشر، الدار الدولية للثرر والتوزيع، الطبعة العربية الثانية.

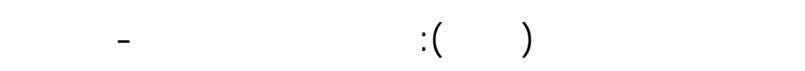

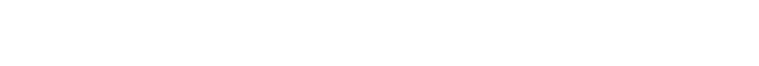

$$
\text { الإسكندرية. }
$$

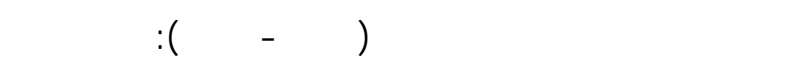
الاقتصاد القيلسي - بين الظرية والظبيق، الدار الجلمعي بة،

الطبعة الثالثة، الإسكندرية.

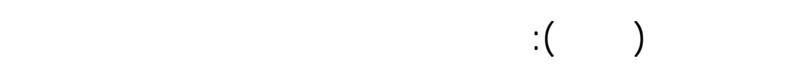

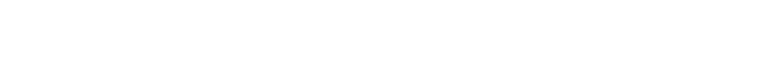
الغذائية _ درلمة مقارنة بين ملبنة الحضنة بالمسيلة وملبذ الارة النل بسطف، قسم إدارة الأعمل والتمية الم ستدلمة، كلي ـة

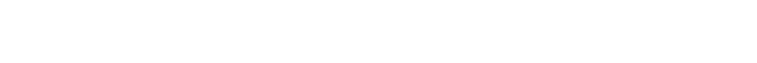

$$
\text { فرحك عبلس بسطف، الجزائر. }
$$

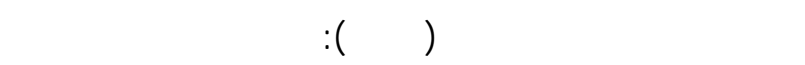

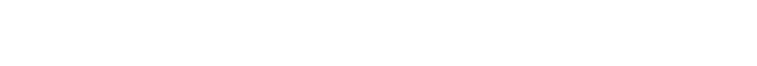

الإسكندرية.

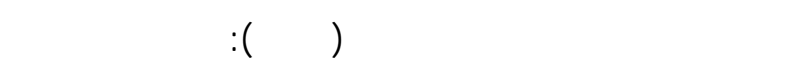

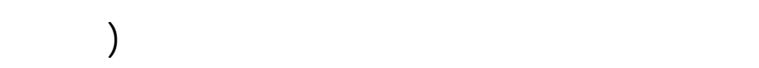

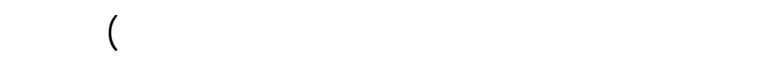

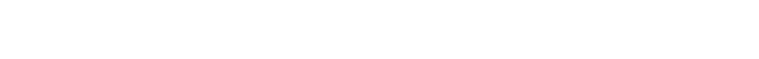

$$
\text { الإسلامية، غزة . }
$$

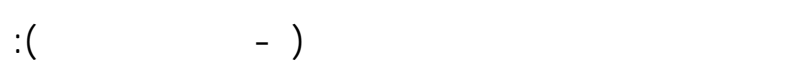
درلسة تحليلية لقيم أداء قطاع الصناعلت الغذائية، المؤتمر

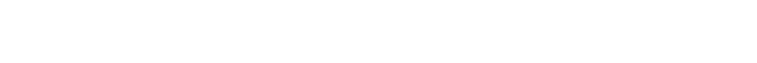
والتحديت المحلية والإقليمية والدولية، القاهرة.
ظروف نشط للثركة الماضية من خ لل نت ائج التحلي لل المالي الساق وفقاً ظاروفها الجيدة.

\section{التوصيلت}

يُوصصي البحث: بقبيق التحليل (الإح صائي والم اللي)

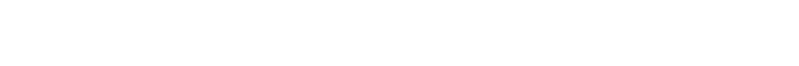

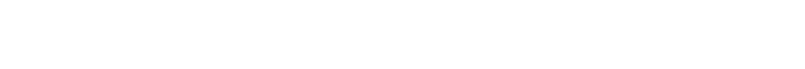

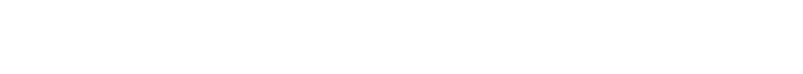
للسيلست الني تختص بمسقبل المدركة وخطة الدولة .

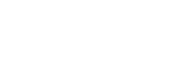

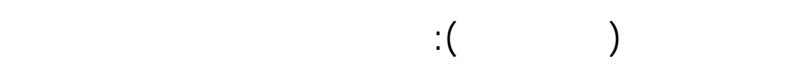
المصرية، الطبعة الرابعة، القاهرة.

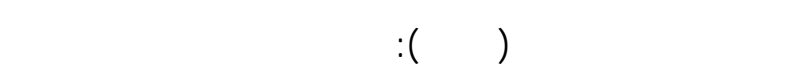
العلمية في المحلسبة وإدارة الأموال، دار الكتب العلمية للنشر النيال

$$
\text { والتوزيع، القاهرة . }
$$

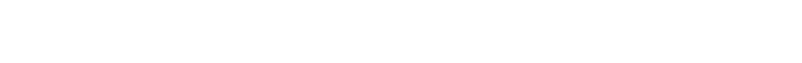

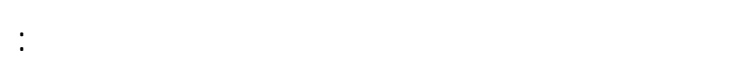
.http://www.gcss-egypt.com/main.htm

الغرفة التجارية الصناعية(جمادي الأوله rاع (هـ ـ):كف ققرأ

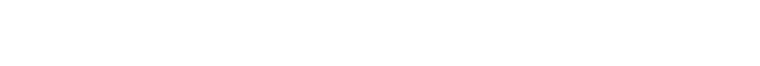

$$
\text { المملكة العربية للسعودية. }
$$

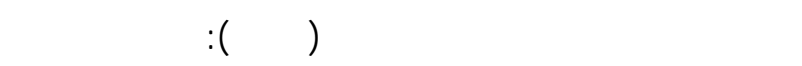

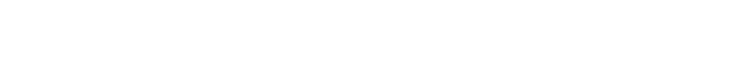

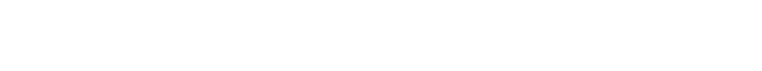

$$
\text { جلمعة الإسكندرية. }
$$

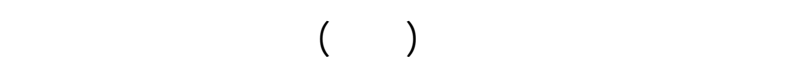

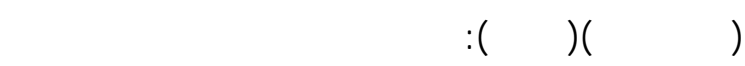

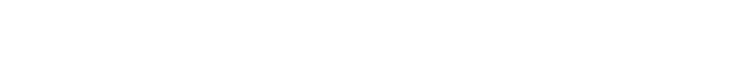
الطبعة الأوله، القاهرة. جيهان مصطفى أحمد مهران(1991 ) ): الكفاعة الاقت صاية ف مي الأي

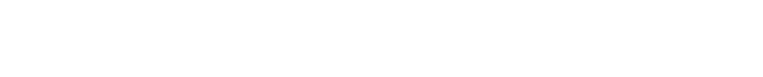

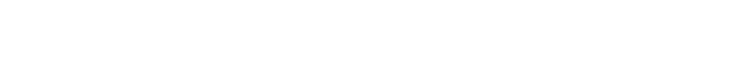
جلمعة الإسكندرية . 
Jan Alpmann, Vera Bitsch(2015): Exit, Voice, and Loyalty in the Case of Farmer Associations: Decision-Making of Dairy Farmers during the German Milk Conflict, International Food and Agribusiness Management Review (IFAMA), Vol .18 , Issue. 4.

R.A. Hill(2008): Strategic Financial Management, ISBN 97887-7681-425-0, Download Free books at BookBoon.com.
M. Houšková Beránková, M. Houška (2011): Data, Information and Knowledge in Agricultural DecisionMaking, Agris on-line Papers in Economics and Informatics, Vol. III , No. 2.

\title{
ABSTRACT \\ The Role of Accounting Data and Information in the Decision- Making Process of the Egyptian Governmental Companies: Case Study of the General Company for Silos and Storage (GCSS)
}

\author{
Sameh M. Shehab
}

The study aimed at analyzing the role of accounting data and information in the decision-making process of grain-public companies companies in Egypt. The case study examined is the General Company for Silos and Storage. Both of the statistical and financial analyses have been used. These analyses are confined to two main sections; the first dealt with the Company's activities pertaining to imported wheat. The second handled the role of data and information in making the Company's decisions.

The study results of the first section disclosed the following: (1) Amounts of wheats imported in $2013 / 2014$ outweighed those imported in 2012/2013 by $32.97 \%$. (2) The main wheat-importing countries of Romania, Russia, and France realized importedamounts' increases of $52.97 \%, 118.47 \%$, and $91.52 \%$, respectively. Whilst both of the USA and the Ukraine have experienced imported-amounts' decline of 78.12\% and 52.64\%, respectively. (3) Wheat imports reaching the ports of Damietta and Alexandria have witnessed wheat-imports' increases of $68.03 \%$ and $56.85 \%$, respectively. Whereas the port of El-Dekhaila has practiced a decline of $20.77 \%$ in wheat imports. The port of Safaga has witnessed no change whatsoever.

The second section, which is typical to the case study examined during the period 2008/20092012/2013, showed the following: (1) Employment rates in the Company have declined significantly despite of offering high wage rates. This is partially because wages occupied a large portion of the Company's cost structure with ratio of wages to returns of $37.61 \%$ in the 2012/2013 budget. (2) The Company suffered from inventory-stock accumulation which is estimated at $6.42 \%$ of the current liabilities. Moreover, capital accumulation is found to be poor with a net fixed-assets ratio of barely $17 \%$ during the average study period. (3) Weak and poor liquidity ratios and self-financing sources are common trajectories in the Company. And (4) depressed sales and collection policies, as indicated to by the ratio of cash to returns of 0.31 during the average study period.

The existing financial and crediting records of the General Company of Silos and Storage indicated to numerous imbalances and shortcomings. These inadequacies could be corrected via the acquiring, implementation, and analysis of upright data bases.

Finally, the study recommends the application of regular financial and statistical analyses of data and accounting information of the company to identify aspects of strengths and weaknesses. Consequently, better decision making and policy formation could be made in accordance with governmental policies.

Keywords: Decision Making, Managerial Efficiency, Data and Information, Financial Indicators. 